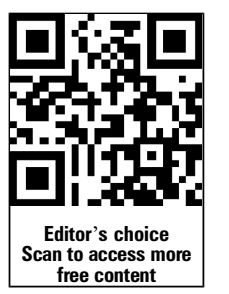

\title{
2014 Female Athlete Triad Coalition Consensus Statement on Treatment and Return to Play of the Female Athlete Triad: \\ 1st International Conference held in San Francisco, California, May 2012 and 2nd International Conference held in Indianapolis, Indiana, May 2013
}

\author{
Mary Jane De Souza, ${ }^{1}$ Aurelia Nattiv, ${ }^{2}$ Elizabeth Joy, ${ }^{3}$ Madhusmita Misra, ${ }_{1}^{4}$ \\ Nancy I Williams, ${ }^{1}$ Rebecca J Mallinson, ${ }^{1}$ Jenna C Gibbs, ${ }^{5}$ Marion Olmsted, ${ }^{6}$ \\ Marci Goolsby, ${ }^{7}$ Gordon Matheson, ${ }^{8}$ Expert Panel
}

- Additional material is published online only. To view please visit the journal online (http://dx.doi.org/10.1136/ bjsports-2013-093218).

For numbered affiliations see end of article.

\section{Correspondence to} Mary Jane De Souza, Department of Kinesiology, Women's Health and Exercise Laboratory, 104 Noll Laboratory, Penn State University, University Park, PA 16802, USA; mjd34@psu.edu

Received 22 October 2013 Revised 4 December 2013 Accepted 6 December 2013
CrossMark

To cite: De Souza MJ, Nattiv $A$, Joy $E$, et al. Br J Sports Med 2014:48:289.

\section{ABSTRACT}

The Female Athlete Triad is a medical condition often observed in physically active girls and women, and involves three components: (1) low energy availability with or without disordered eating, (2) menstrual dysfunction and (3) low bone mineral density. Female athletes often present with one or more of the three Triad components, and an early intervention is essential to prevent its progression to serious endpoints that include clinical eating disorders, amenorrhoea and osteoporosis. This consensus statement represents a set of recommendations developed following the 1st (San Francisco, California, USA) and 2nd (Indianapolis, Indiana, USA) International Symposia on the Female Athlete Triad. It is intended to provide clinical guidelines for physicians, athletic trainers and other healthcare providers for the screening, diagnosis and treatment of the Female Athlete Triad and to provide clear recommendations for return to play. The 2014 Female Athlete Triad Coalition Consensus Statement on Treatment and Return to Play of the Female Athlete Triad expert panel has proposed a risk stratification point system that takes into account magnitude of risk to assist the physician in decision-making regarding sport participation, clearance and return to play. Guidelines are offered for clearance categories, management by a multidisciplinary team and implementation of treatment contracts. This consensus paper has been endorsed by the Female Athlete Triad Coalition, an International Consortium of leading Triad researchers, physicians and other healthcare professionals, the American College of Sports Medicine and the American Medical Society for Sports Medicine.

\section{INTRODUCTION}

This consensus statement is the first of its kind and represents a set of recommendations developed following the 1st (San Francisco, California, USA) and 2nd (Indianapolis, Indiana, USA) International Consensus Meetings on the Female Athlete Triad (Triad). It is intended to provide clinical guidelines for physicians, athletic trainers and other healthcare providers for the treatment of the Triad and to provide clear recommendations for return to play. The Consensus recommendations herein were developed using a consensus-based approach similar to that utilised by the International Consensus
Statement on Concussion. ${ }^{1}$ This consensus statement will serve as a supplement to the American College of Sports Medicine (ACSM) revised position stand on the Triad published in 2007. The 2007 position stand provided the scientific evidence documenting the existence and causes of the Triad. ${ }^{2}$ Practical information for athletes, coaches, parents and a list of resources and helpful information on the Triad can be readily viewed on the Female Athlete Triad Coalition website at http://www. femaleathletetriad.org. This consensus paper has been endorsed by The Female Athlete Triad Coalition, an International Consortium of leading Triad researchers, physicians and other healthcare professionals, the American College of Sports Medicine and the American Medical Society for Sports Medicine.

While agreement exists concerning the primary guidelines and recommendations communicated in this document, the authors acknowledge that the underlying levels of scientific evidence regarding some elements of the Triad, particularly related to treatment strategies, are still evolving. The treatment guidelines and return-to-play recommendations proposed herein are based on the published literature available to date, with consensus from the international team of experts convened at the two meetings. As such, management and return-to-play decisions should be based on informed clinical judgement keeping in mind individual risk factors and concerns as described herein.

\section{DEFINITION OF THE FEMALE ATHLETE TRIAD MODEL}

The Triad is a medical condition often observed in physically active girls and women, and involves any one of the three components: (1) low energy availability (EA) with or without disordered eating (DE), (2) menstrual dysfunction and (3) low bone mineral density $(\mathrm{BMD})^{2}$ (see figure 1$)$. Female athletes often present with one or more of the three Triad components, and an early intervention is essential to prevent its progression to serious endpoints that include clinical eating disorders (EDs), amenorrhoea and osteoporosis. ${ }^{2}$

In 1997, the Task Force on Women's Issues of ACSM published the first Triad position stand which described a syndrome of three distinct but 


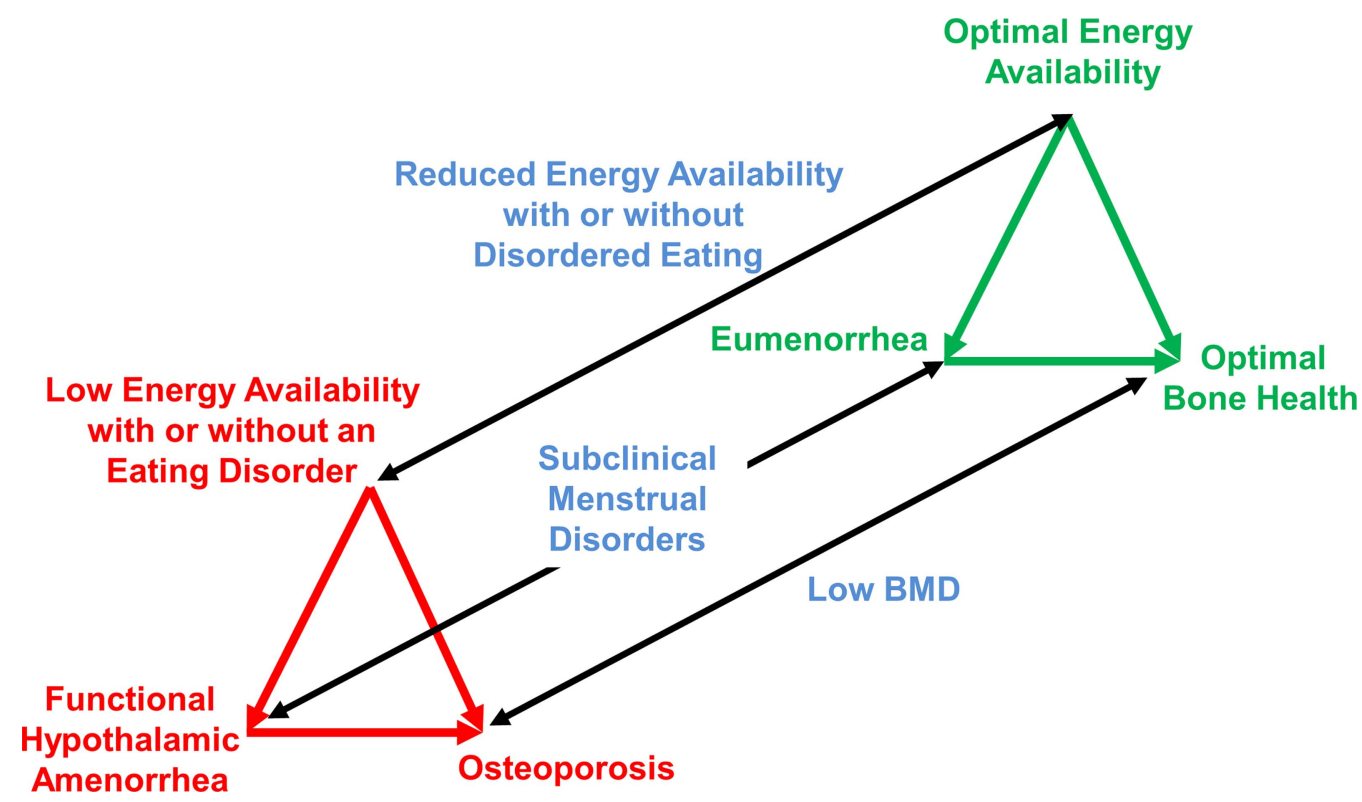

Figure 1 Spectra of the Female Athlete Triad. The three inter-related components of the Female Athlete Triad are energy availability, menstrual status and bone health. Energy availability directly affects menstrual status, and in turn, energy availability and menstrual status directly influence bone health. Optimal health is indicated by optimal energy availability, eumenorrhoea and optimal bone health, whereas, at the other end of the spectrum, the most severe presentation of the Female Athlete Triad is characterised by low energy availability with or without an eating disorder, functional hypothalamic amenorrhoea and osteoporosis. An athlete's condition moves along each spectrum at different rates depending on her diet and exercise behaviours. BMD, bone mineral density. ${ }^{2}$ Adapted with permission from Lippincott Williams and Wilkins/Wolters Kluwer Health: Medicine and Science in Sport and Exercise. ${ }^{2}$

inter-related conditions: DE, amenorrhoea and osteoporosis. ${ }^{3}$ Subsequent cross-sectional studies defined the Triad based on critical endpoints for each of the three Triad components to include ED, amenorrhoea and osteoporosis. The components of the Triad are known to be inter-related since energy deficiency associated with DE plays a causal role in the development of menstrual disturbances, ${ }^{4-6}$ and an energy deficiency and a hypoestrogenic environment associated with amenorrhoea play a causal role in low BMD. ${ }^{7-10}$

In studies conducted after the publication of the 1997 Triad position stand, investigators identified negative health consequences of the Triad associated with subclinical/less severe conditions than the aforementioned clinical endpoints. Reports of a high prevalence of subclinical menstrual disturbances, including luteal phase defects and anovulatory cycles, were observed in athletes and recreationally active women. ${ }^{11}{ }^{12}$ Investigators have documented mild-to-moderate low BMD among athletes with oligomenorrhoea and subclinical menstrual disturbances (ie, anovulation and luteal phase defects). ${ }^{13}{ }^{14}$ Other investigators have identified that a delay in menarche, ${ }^{15} 16$ a history of oligomenorrhoea and amenorrhoea ${ }^{17-19}$ and/or low BMD (not just osteoporosis) were significant risk factors for stress fractures and bone stress injury in athletes ${ }^{17} 1^{18} \quad 20$ and female military recruits. $^{21} 22$ Findings from controlled laboratory studies indicated that low EA caused hormone disruptions characterised by suppressed metabolic and reproductive hormones, suppressed bone formation and increased bone resorption. ${ }^{9}$ 23-25 A causal relationship for the induction of menstrual disorders associated with low EA was carefully documented in the literature. ${ }^{5} 2627$ The reversal of amenorrhoea was also demonstrated to be related to EA. ${ }^{5} 27$ Therefore, to better reflect the most recent research, as well as to more comprehensively identify athletes at risk for developing negative health consequences, there was a clear need to revise the 1997 definition of the Triad.
In 2007, the Triad was redefined as a syndrome of low EA with or without DE, functional hypothalamic amenorrhoea (FHA) and osteoporosis. ${ }^{2}$ EA is defined conceptually and behaviourally as the amount of dietary energy remaining after exercise training for all other physiological functions each day. ${ }^{28}$ The new Triad model represented each component as the pathological endpoint of one of the three inter-related spectrums ranging from a healthy endpoint to subclinical and clinical conditions. $^{2}$ At the 'healthy' end of the continuum, each Triad component is optimised, that is, EA meets total energy expenditure, reproductive and bone health needs; ovulatory menstrual cycles are maintained and bone mass is normal. ${ }^{2}$ At the 'unhealthy' end of the continuum, each Triad component presents the clinical endpoints of the syndrome, including low EA with or without DE, FHA and osteoporosis. ${ }^{2}$

The goal in presenting Triad conditions along a spectrum was to highlight the importance of recognising athletes who exhibit subclinical abnormalities and thus allow for early intervention. The Panel supports the notion that prevention and early intervention remains the key to avoid the more serious clinical endpoints of the Triad (ie, ED, amenorrhoea or osteoporosis). Furthermore, given the recent focus on subclinical menstrual disturbances and bone-related concerns, the panel agreed that the 2007 presentation of the Triad model as a spectrum is most appropriate and most useful for designing treatment and return-to-play guidelines.

\section{HEALTH CONSEQUENCES ASSOCIATED WITH THE TRIAD Why is the Triad harmful to an athlete's health?}

Chronic low EA can have significant effects on health and physical performance, particularly when a clinical ED is present. ${ }^{29}$ Low EA plays a causal role in the induction of exercise-associated menstrual disturbances. ${ }^{5}{ }^{30}$ Hypoestrogenemia associated with prolonged reproductive suppression can negatively impact 
musculoskeletal and cardiovascular health. ${ }^{7} 3132$ Low EA can also have negative musculoskeletal effects independent of hypoestrogenism. ${ }^{78}$ Bone stress injuries, including the spectrum of stress reactions and stress fractures, are more common in female athletes with menstrual irregularities and/or low BMD, ${ }^{15-}$ 20 as well as female military recruits. ${ }^{21} 22$ Bone stress injuries also sideline female athletes and reduce competitive performance. Poorer sport performance has been documented in junior elite swimmers who exhibited ovarian suppression and evidence of energy deficiency when compared with their normally cycling counterparts. ${ }^{33}$ Other medical complications of Triad disorders can extend to the endocrine, gastrointestinal, renal and neuropsychiatric systems. ${ }^{2}{ }^{34-36}$ A complete discussion of the health consequences of the Triad is beyond the scope of this paper and can be found elsewhere. ${ }^{2} 37$

\section{SCREENING, RISK STRATIFICATION AND DIAGNOSIS OF THE TRIAD}

What are the best tools to screen for the Triad?

Early detection of athletes at risk is critical to prevent the Triad. Screening for the Triad should be undertaken as part of the Pre-Participation Physical Evaluation (PPE). ${ }^{38-40}$ The PPE should include questions that address all aspects of the Triad spectrums. The current standard screening PPE form, endorsed jointly by six US medical societies, ${ }^{41}$ includes nine questions related to the Triad. Likewise, the International Olympic Committee (IOC)-endorsed Periodic Health Examination ${ }^{40}$ proposes eight questions to screen girls and young women for the Triad.

Although there is limited evidence related to the efficacy of screening questions, ${ }^{42}$ the Consensus Panel recommended that female athletes undergo annual screening with the Triad-specific self-report questionnaire displayed in box 1 , followed by a more in-depth evaluation if the athlete has or is at risk for any Triad component. While such screening is most typically completed at the collegiate level, the Panel recommended screening for younger athletes (high school age) as well. ${ }^{43}{ }^{44} \mathrm{~A}$ major point that the Panel emphasised is that existence of any one Triad component should prompt more thorough investigation for the others. Screening and early intervention in adolescent females

\section{Box 1 Triad Consensus Panel Screening Questions*}

- Have you ever had a menstrual period?

- How old were you when you had your first menstrual period?

-When was your most recent menstrual period?

- How many periods have you had in the past 12 months?

- Are you presently taking any female hormones (oestrogen, progesterone, birth control pills)?

- Do you worry about your weight?

- Are you trying to or has anyone recommended that you gain or lose weight?

- Are you on a special diet or do you avoid certain types of foods or food groups?

- Have you ever had an eating disorder?

- Have you ever had a stress fracture?

- Have you ever been told you have low bone density (osteopenia or osteoporosis)?

*The Triad Consensus Panel recommends asking these screening questions at the time of the sport pre-participation evaluation. for components of the Triad are especially important when one considers that $90 \%$ of peak bone mass is attained by 18 years of age, ${ }^{45}$ thereby providing a window of opportunity for optimising bone health.

\section{What are the most important risk factors to screen for?}

The Panel stated that the risk factors that should be assessed for the Triad include: (1) history of menstrual irregularities and amenorrhoea $^{246}$; (2) history of stress fractures ${ }^{246}$; (3) history of critical comments about eating or weight from parent, coach or teammate $4^{47}$; $(4)$ a history of depression ${ }^{49-51}$; (5) a history of dieting $^{51}{ }^{52}$; (6) personality factors (such as perfectionism and obsessiveness) ${ }^{53-55}$; (7) pressure to lose weight and/or frequent weight cycling ${ }^{52} ;(8)$ early start of sport-specific training ${ }^{52}$; (9) overtraining $^{52}$; (10) recurrent and non-healing injuries ${ }^{56}$ and (11) inappropriate coaching behaviour. ${ }^{52} 54$ Physical examination signs such as low body mass index (BMI), weight loss, orthostatic hypotension, lanugo, hypercarotenaemia, or other signs of an $\mathrm{ED}$, such as parotid gland swelling and callus on the proximal interphalangeal joints (also known as Russell's sign), should also prompt further evaluation. Obtaining an accurate menstrual history is important, starting from age of menarche to the current and the past menstrual patterns, noting months of consecutive missed menses and the number of menses per year since menarche. ${ }^{4157}$ Evaluation of secondary amenorrhoea in girls can begin after 3 months or more of missed menses. ${ }^{57}$ A medication history should be obtained, including medications which may affect menstruation and/or BMD, such as oral contraceptive pills or other contraceptive agents, such as depot medroxyprogesterone acetate. ${ }^{58}$ A history of physician diagnosed bone stress injuries and other fracture history should be noted, ${ }^{41}$ as well as a family history of ED, osteoporosis ${ }^{59}$ and/or fractures.

\section{DIAGNOSIS OF THE TRIAD}

\section{How are Triad conditions diagnosed?}

Following screening, accurate diagnosis of any of the Triad disorders is dependent on a thorough evaluation of the athlete by the physician and other members of an experienced multidisciplinary healthcare team. Members of the multidisciplinary team should include a physician, a sports dietitian (a registered dietitian, who preferably is a board certified specialist in sports dietetics) ${ }^{60}{ }^{61}$ and a mental health professional, if the athlete has DE or a clinical ED. Other members of the team may include an exercise physiologist, certified athletic trainer and medical consultants.

The Consensus Panel agreed that essential to the process of screening, evaluation, diagnosis and treatment is the athlete's honesty and willingness to participate in each of these steps. Each member of the multidisciplinary team must develop a therapeutic alliance with the athlete. The process of engagement and active participation in treatment is often ongoing, reflecting the challenges of restoring adequate EA. The panel emphasised that written policies regarding screening, evaluation and treatment of the Triad need to be reviewed with athletes and their parents, and supported by coaches and administrators.

How is low EA diagnosed? The Panel emphasised that low EA cannot be diagnosed by estimating energy balance because athletes who have been in a state of negative energy balance may experience a suppression of physiological functions that restores energy balance and weight stability. ${ }^{2}$ Weight stability has been reported in amenorrhoeic athletes. ${ }^{62-65}$ Thus, an athlete could be in a state of energy balance but also in a state of low EA at the same time, and a stable body weight should not be used as an indicator of adequate EA. 
As a first pass, overt signs of low EA can be indicated by low energy stores such as a BMI $<17.5 \mathrm{~kg} / \mathrm{m}^{2}$ or in adolescents $<85 \%$ of expected body weight. In adolescents, absolute BMI cut-offs should not be used. The BMI percentile method for calculating estimated body weight examines an adolescent's weight in relation to the 50th BMI percentile (which is their expected body weight). ${ }^{66}$ Deviations for this point are used as an indicator of medical stability to set a target weight and to assess progress in adolescents with DE and ED. ${ }^{66}$ BMI percentiles adjusted for age and gender are recommended until age 20 by the Centers for Disease Control and Prevention (http://www. cdc.gov/growcharts). When body weight is not particularly low, more detailed information regarding food intake and energy expenditure is necessary to diagnose low EA. Other markers of low EA in the absence of DE and recent weight loss that should be explored include physiological signs of adaptation to chronic energy deficiency, such as reduced resting metabolic rate (RMR), ${ }^{4}$ low triiodothyronine (low T3) ${ }^{4} 67$ and a ratio of measured RMR/predicted RMR less than $0.90 .^{7}$ 68-70

It is important to note that methods for assessing EA, dietary intake and energy expenditure are improving but are imprecise. An experienced sports dietitian or an exercise physiologist can help provide expertise on completing these assessments. A particular index of daily EA is defined as energy intake (kcal) minus exercise energy expenditure (kcals) divided by kilograms of fat-free mass (FFM) or lean body mass. ${ }^{28}$ This index has been significantly associated with changes in reproductive ${ }^{6} 24$ and metabolic hormone concentrations and markers of bone formation and resorption ${ }^{9}$ that occur in controlled laboratory experiments where EA is manipulated using varying combinations of reductions in food intake and increases in exercise energy expenditure in women. From these short-term experiments, a threshold below which detrimental physiological changes in reproductive function, metabolism and bone occur has been identified as $30 \mathrm{kcal} / \mathrm{kg}$ of FFM/day. ${ }^{6}$ The Panel noted that outside the laboratory, determination of EA using this index is more difficult and is dependent on less precise measures of exercise energy expenditure, dietary energy intake and body composition (weight and per cent fat). Strategies to estimate dietary intake include 3-day, 4-day and 7-day dietary logs, $24 \mathrm{~h}$ dietary recall and food-frequency questionnaires. ${ }^{71}$ Regardless of the method chosen, accurate assessment of dietary intake can be challenging due to a number of factors such as underreporting of intake, modified intake during the period of reporting and imprecise recording of portion sizes. ${ }^{71}$ Ideally, athletes thought to be at risk for nutritional deficiencies should undergo a comprehensive nutrition assessment by a registered sports dietitian. ${ }^{61}$ Actual estimates of energy expenditure can be accomplished using heart rate monitors and accelerometers, ${ }^{28}$ but practical estimates of exercise energy expenditure are also available, and are dependent on self-report. There are numerous web-based calculators of exercise energy expenditure; however, the Panel recommends that the 2011 Compendium of Physical Activities be used to calculate exercise energy expenditure, whereby kilocalories of energy expenditure $=$ metabolic equivalent of task $\times$ weight in kilograms $\times$ duration of activity in hours. ${ }^{72}$ All methods of estimating energy expenditure have an error associated with them, and any directional bias needs to be considered on an individual basis. ${ }^{73}$ The third component of the EA equation is kilograms of FFM, which is obtained from measurement of body weight in kilograms, and from an estimate of body fatness. Various methods can be used to estimate body fat. Dual-energy X-ray absorptiometry (DXA) is a precise method and widely available ${ }^{74}$; other clinically accessible methods commonly used among athletes include airdisplacement plethysmography, skin fold measurements and bioelectrical impedance. ${ }^{75}$ Having gathered the aforementioned data, one can access the EA Calculator provided on the Female Athlete Triad Coalition website (http://www.femaleathletetriad. org/calculators/) to estimate EA. Ideally, physically active women should aim for at least $45 \mathrm{kcal} / \mathrm{kg}$ of FFM/day of energy intake to ensure adequate EA for all physiological functions. ${ }^{2} 28$

How is amenorrhoea diagnosed? The Panel explained that athletes and physically active women presenting with primary or secondary amenorrhoea require evaluation to rule out pregnancy and endocrinopathies since no single blood test can confirm a diagnosis. The diagnosis of FHA in athletes secondary to low EA is a diagnosis of exclusion. An algorithm, modified from the Jameson and De Groot textbook of endocrinology ${ }^{76}$ for the diagnosis of primary/secondary amenorrhoea can be viewed in figure 2. Endocrinopathies that must be ruled out include (1) thyroid dysfunction, (2) hyperprolactinaemia, (3) primary ovarian insufficiency, (4) hypothalamic and pituitary disorders (genetic or acquired), (5) hyperandrogenic conditions including polycystic ovary syndrome, virilising ovarian tumours, adrenal tumours, non-classic congenital adrenal hyperplasia and Cushing's syndrome. ${ }^{77} 78$ Outflow tract obstruction is important to rule out in patients with primary amenorrhoea. The most common causes of amenorrhoea are usually identified following a thorough medical history, physical examination, a pregnancy test, as well as evaluation of thyroid stimulating hormone, follicle stimulating hormone and prolactin, to assess for thyroid disease, primary ovarian insufficiency and hyperprolactinaemia. A serum oestradiol and/or a progesterone challenge test (medroxyprogesterone acetate $10 \mathrm{mg}$ for 10 days) may be useful to assess the degree of hypoestrogenism. If there is physical evidence of androgen excess (ie, hirsutism, acne and androgenic alopecia), additional laboratory testing may include total and free testosterone, and dehydroepiandrosterone and its sulfate (DHEA/S). An early morning 17-hydroxyprogesterone may be obtained in those with hyperandrogenism to assess for nonclassic 21-hydroxylase deficiency (the most common cause of congenital adrenal hyperplasia) on initial or follow-up testing. A pelvic ultrasound may be obtained in those with clinical or biochemical hyperandrogenism to confirm polycystic ovaries or to rule out virilising ovarian tumours. ${ }^{77} 79$ The primary care physician should refer to or consult with an endocrinologist for endocrine disorders they are not experienced in diagnosing or treating.

How is low BMD diagnosed? The Panel has utilised the definitions published by the International Society of Clinical Densitometry (ISCD) for low BMD and osteoporosis in children and adolescents (see box 2) and for premenopausal women (see box 3$)^{80}$ as well as ACSM suggested criteria for female athletes involved in regular weight-bearing sports. ${ }^{2}$ Criteria are described below for who and what site should be considered for a DXA scan and how often DXA should be performed.

\section{Who should get DXA scans for BMD testing}

The Panel agreed that indications for obtaining a DXA scan for BMD testing in an athlete should follow the Triad risk stratification (see Clearance and Return to Play section) and include the following:

1. $\geq 1$ 'High risk' Triad Risk Factors:

- History of a DSM-V diagnosed ED ${ }^{81}$

- BMI $\leq 17.5 \mathrm{~kg} / \mathrm{m}^{2},<85 \%$ estimated weight, OR recent weight loss of $\geq 10 \%$ in 1 month

- Menarche $\geq 16$ years of age 


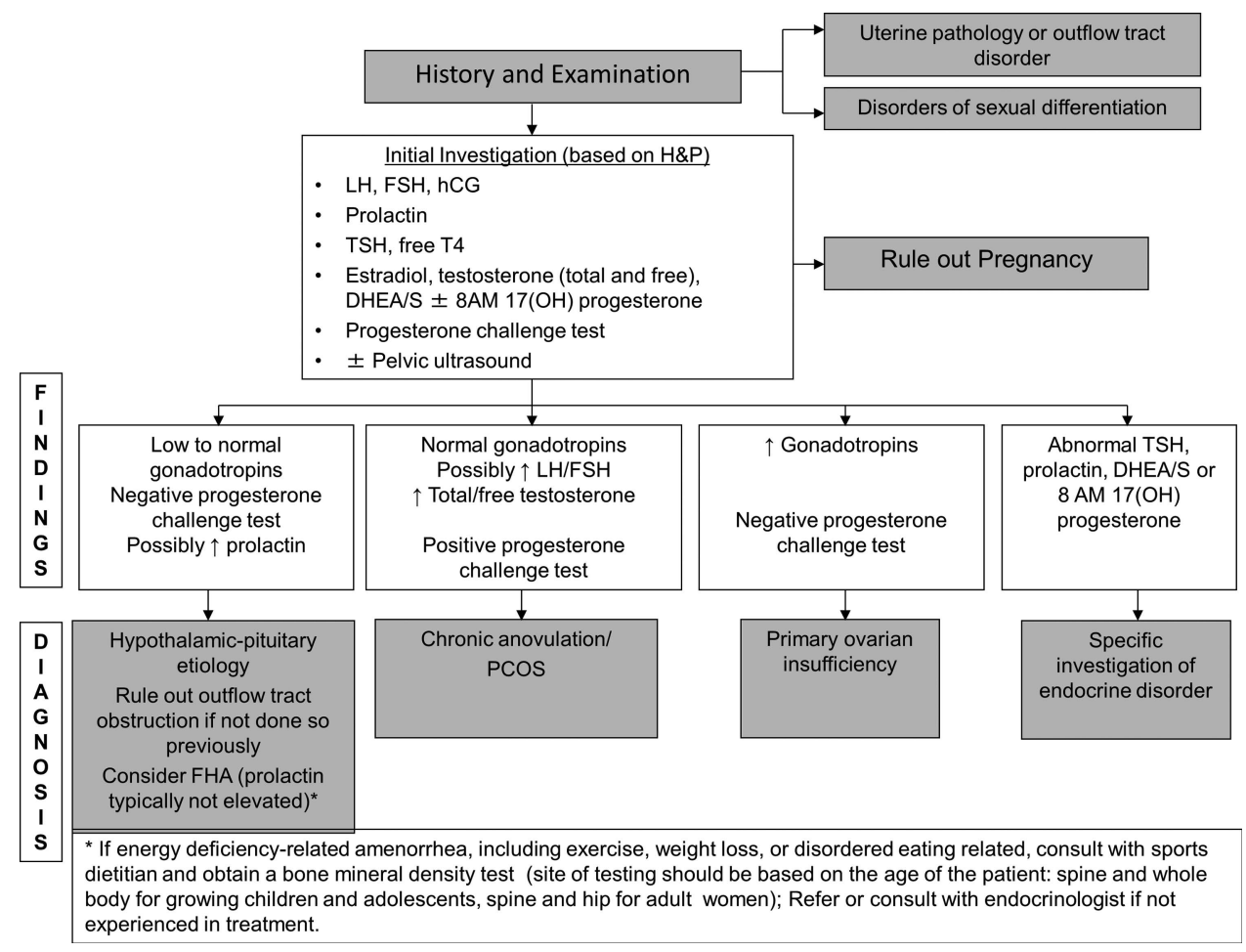

Figure 2 Amenorrhoea algorithm. Recommended clinical evaluation of an athlete with primary or secondary amenorrhoea, or prolonged oligomenorrhoea, includes a history and physical examination, initial and follow-up laboratory testing and diagnosis by a physician. Referral or consultation with endocrinology is recommended if the diagnosing physician is not experienced with treatment of functional hypothalamic amenorrhoea or other aetiologies of amenorrhoea. DHEA/S, dehydroepiandrosterone sulfate; FHA, functional hypothalamic amenorrhoea; FSH, follicle-stimulating hormone; hCG, human chorionic gonadotropin; LH, luteinizing hormone; PCOS, polycystic ovarian syndrome; TSH, thyroid-stimulating hormone. Modified from Illingworth. ${ }^{76}$

- Current or history of $<6$ menses over 12 months

- Two prior stress reactions/fractures, one high-risk stress reaction/fracture (see figure 4), or a low-energy nontraumatic fracture 188283

- Prior Z-score of $<-2.0$ (after at least 1 year from baseline DXA)

OR

2. $\geq 2$ "Moderate risk" Triad Risk Factors:

- Current or history of DE for 6 months or greater

- BMI between 17.5 and $18.5,<90 \%$ estimated weight, OR recent weight loss of $5-10 \%$ in 1 month

- Menarche between ages 15 and 16 years

- Current or history of 6-8 menses over 12 months

- One prior stress reaction/fracture

- Prior Z-score between -1.0 and -2.0 (after at least 1 year interval from baseline DXA)

3. In addition, an athlete with a history of $\geq 1$ non-peripheral or $\geq 2$ peripheral long bone traumatic fractures (non-stress) should be considered for DXA testing if there are one or more moderate or high-risk Triad risk factors (see figure 4). This will depend on the likelihood of fracture given the magnitude of the trauma (low or high impact) and age at which the fracture occurred. Athletes on medications for 6 months or greater that may impact bone (such as depot medroxyprogesterone acetate, oral prednisone and others), ${ }^{84}$ should also be considered for DXA testing.

\section{How often should athletes get DXA testing}

The Panel agreed that the frequency of BMD assessment by DXA will depend on the initial BMD and ongoing clinical status of the athlete. We agree with the ISCD 2013 guidelines that repeat DXA screening should be obtained when the expected change in BMD Z-scores equals or exceeds the least significant change. ${ }^{85}$ Those with definitive indications for DXA testing may require BMD testing every 1-2 years to determine whether there is ongoing bone loss, and to evaluate treatment.

\section{Which sites should be screened with a DXA scan}

BMD Z-scores (and not T-scores) should be reported for all children, adolescents and premenopausal women.

1. Adult women $\geq 20$ years

- Weight-bearing sites (posteroanterior spine, total hip, femoral neck)

- Non-weight-bearing sites, namely the radius (33\%) if weight-bearing sites cannot be assessed for any reason

2. Children, adolescents and young women $<20$ years

- Posteroanterior lumbar spine bone mineral content (BMC) and areal BMD

- Whole body less head if possible (otherwise whole body) $\mathrm{BMC}$ and areal $\mathrm{BMD}^{80}$

- Adjust for growth delay (with height or height age) or maturational delay (with bone age)

- Use paediatric reference data, and when possible, report height-adjusted Z-scores. ${ }^{86}$

NON-PHARMACOLOGICAL TREATMENT GUIDELINES FOR

THE CLINICAL SEQUELAE ASSOCIATED WITH THE TRIAD

What evidence exists in support of non-pharmacological treatment strategies?

Documentation of weight gain and restoration of menstrual function following amenorrhoea has been provided by 
Box 2 Definition of low bone mineral density (BMD) and osteoporosis in children and adolescents (ages 5-19)

The diagnosis of osteoporosis in children and adolescents requires the presence of both a clinically significant fracture history AND low bone mineral content (BMC) or low BMD

- A clinically significant fracture history is one or more of the following:

- Long bone fracture of the lower extremities.

- Vertebral compression fracture.

- Two or more long-bone fractures of the upper extremities.

- Low BMC or BMD* is defined as a BMC or areal BMD Z-score that is $\leq-2.0$, adjusted for age, gender and body size, as appropriate.

Source: Lewiecki et al. ${ }^{80}$

${ }^{*}$ American College of Sports Medicine (ACSM) defines low BMC or BMD as a Z-score that is less than -1.0 in female athletes in weight-bearing sports. ${ }^{2}$

Kopp-Woodroffe $e a^{87}$ and Dueck et $a l^{88}$ in case studies, in a retrospective analysis of female athletes following a clinical intervention ${ }^{89}$ and in experiments in female cynomolgus monkeys. ${ }^{5}$ Studies in anorexic women demonstrate the efficacy of weight gain (and fat mass) for restoration of menses. ${ }^{90-93}$ In case studies of five amenorrhoeic athletes and recreationally active women in whom energy intake was increased via consumption of a sport nutrition beverage (approximately $360 \mathrm{kcal} /$ day) and exercise training was reduced by 1 day/week for $12-$ 20 weeks, weight gain of 1-3 kg was observed and three of the five women resumed menses. ${ }^{87} 88$ In a 1-year prospective case study of two amenorrhoeic athletes undergoing controlled increased energy intake, recovery of menses coincided closely with increases in caloric intake and weight gain; body weight increased by $2.8 \mathrm{~kg}(5 \%)$ and $4.2 \mathrm{~kg}(8 \%)$ at 12 months in the two participants. ${ }^{94}$ In a 5 -year retrospective study of college athletes undergoing non-pharmacological therapy, Arends et al ${ }^{89}$ reported a significant increase in weight of $9 \%$ (mean weight gain: $5.3 \pm 1.1 \mathrm{~kg}$ ) in the $17.6 \%$ oligomenorrhoeic or amenorrhoeic athletes who resumed menstrual function (mean time to recovery: $15.6 \pm 2.6$ months) versus minimal weight gain (weight gain of $1.3 \pm 1.1 \mathrm{~kg}$ ) in those who did not resume menses. Causal evidence of the efficacy of increased energy intake to

Box 3 Definition of low bone mineral density (BMD) and osteoporosis in premenopausal women

- The diagnosis of osteoporosis in premenopausal women cannot be diagnosed on the basis of BMD alone.

- A BMD Z-score of $\leq-2.0^{*}$ is defined as 'below the expected range for age'.

- A BMD Z-score above -2.0 is 'within the expected range for age'.

- Osteoporosis is diagnosed if there is a BMD Z-score of $\leq-2.0$ plus secondary causes of osteoporosis.

Source: Lewiecki et al. ${ }^{80}$

*American College of Sports Medicine (ACSM) defines low bone mineral content or BMD as a Z-score that is less than -1.0 in female athletes in weight-bearing sports. ${ }^{2}$ reverse menstrual disturbances was provided by Williams $e t a l^{5}$ in female cynomolgus monkeys who demonstrated that restoration of menses was accompanied by an average weight gain of $5.7 \%$.

Weight gain that leads to recovery of menstrual function is linked to improvement of other clinical outcomes characteristic of exercise-associated amenorrhoea including low BMD ${ }^{90} 9596$ and impaired endothelial function. ${ }^{97}$ More research is necessary to establish the time course of weight changes and the sensitivity, specificity and success of nutritional and dietary interventions.

\section{What are the components of non-pharmacological treatment for each Triad condition?}

Owing to the multifactorial aetiology of the Triad, the Panel has established that an optimal treatment approach must address the underlying cause of the Triad, that is, low EA. ${ }^{2}$ Energy status must be normalised primarily through modifications of diet and exercise training, if necessary, with the goal of increasing EA. ${ }^{2} 29$ The consensus of our recommendations is focused on restoration or normalisation of body weight as the best strategy for successful resumption of menses and improved bone health. ${ }^{2} 89909698$ The Panel noted that the development of any Triad treatment plan should include a consideration of the goals of the athlete, her unique diet and training practices, any coexisting conditions and a system for monitoring changes.

Specific non-pharmacological recommendations for interventions in athletes with low EA

Specific treatment recommendations developed by the Panel depend on identifying how low EA developed in the athlete. There may be four unique pathways to low EA, and as such, four unique treatment recommendations.

1. If the cause of low EA is inadvertent undereating, then referral for nutritional education is sufficient. Nutritional education should ideally include a sports dietitian. An exercise physiologist can also complete an assessment of energy expenditure and EA.

2. If the cause for low EA is DE, the referral should be to a physician and for nutritional counselling with a sports dietitian.

3. If the cause for low EA is intentional weight loss without $\mathrm{DE}$, then referral for nutritional education is sufficient.

4. If the cause for low EA involves clinical ED, treatment should include evaluation and management with a physician, nutritional counselling with a sports dietitian and referral to a mental health practitioner for psychological treatment. ${ }^{2} 99$ In this case, the reversal of low EA will not be possible without psychological treatment. ${ }^{299-102}$

In general, the primary goal of treatment is to restore or normalise body weight, concomitant with an improvement in overall nutritional and energetic status. ${ }^{2} 103104$ When DE is apparent, the Panel emphasised that the treatment plan in these athletes must focus on the modification of unhealthy attitudes, behaviours and emotions related to food and body image that may perpetuate the DE. ${ }^{101} 103104$ Weight gain is a primary concern for athletes with FHA who are underweight and it is important to emphasise that the amount of weight gain that typically leads to resumption of menses is variable among individuals. ${ }^{87} 8894$ In studies thus far, a range of approximately $5-10 \%$ of body weight or $1-4 \mathrm{~kg}$ of weight gain has been observed. ${ }^{878894}$ This weight gain is often comprised of gains in fat mass in anorexic women, ${ }^{91-93}$ but in exercising women without clinical ED, gains in FFM have also been observed. ${ }^{87} 94$ 


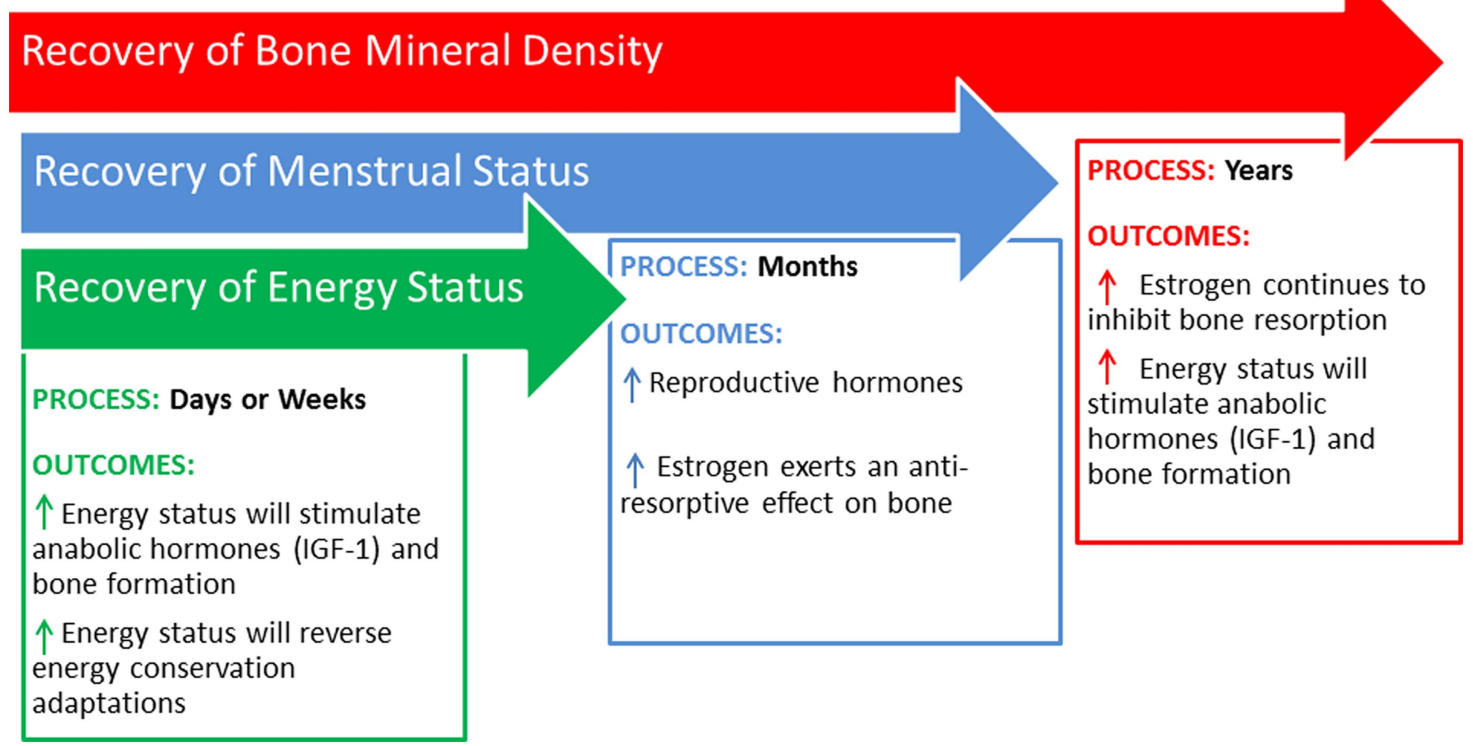

Figure 3 Treatment of the Female Athlete Triad. The three components of the Triad recover at different rates with the appropriate treatment. Recovery of energy status is typically observed after days or weeks of increased energy intake and/or decreased energy expenditure. Recovery of menstrual status is typically observed after months of increased energy intake and/or decreased energy expenditure, which improves energy status. Recovery of bone mineral density may not be observed until years after recovery of energy status and menstrual status has been achieved. IGF-1, insulin-like growth factor-1.

Treatment targets for low EA

The Panel identified that targets of treatment are varied and depend on individual circumstances. Specific treatment targets may include one or more of the following:

- Reversal of recent weight loss ${ }^{105}$;

- Return to a body weight associated with normal menses ${ }^{90-94}$;

- Weight gain to achieve a BMI of $\geq 18.5 \mathrm{~kg} / \mathrm{m}^{2}$ or $\geq 90 \%$ of predicted weight ${ }^{9091100106107}$;

- Energy intake should be set at a minimum of $2000 \mathrm{kcal} / \mathrm{day}$; or more likely, a greater energy intake will be required, depending on exercise energy expenditure. ${ }^{94} 108$

Since the treatment goal is to restore or normalise body weight, the Panel recommended an increase in dietary energy intake, a decrease in exercise energy expenditure, or both. Recommendations should consider individual preferences and may depend on where the athlete is in the competitive season (reductions in training volume may not be feasible in season; acceptance of increased energy intake may be better received vs reduction in training volume). Prescribed changes in energy intake to achieve an increased BMI and/or body weight goal should be gradual, beginning with an approximately 20-30\% increase in caloric intake over baseline energy needs, or the amount of energy required to gain approximately $0.5 \mathrm{~kg}$ every 7-10 days. ${ }^{878894}$ For an athlete consuming $2000 \mathrm{kcal} /$ day, this would represent a gradual increase of 200-600 kcal/day, accomplished over several months. If EA (intake kcal-exercise kcal)/kg of FFM can be reliably estimated, the target should be at or greater than $45 \mathrm{kcal} / \mathrm{kg}$ of FFM. Specific strategies that have been successful in female athletes have been detailed in case study investigations. ${ }^{878894}$

\section{Steps in a plan to increase EA}

Step 1: Perform an assessment of baseline energy needs that includes a thorough body weight history including questions about associated changes in menstrual status. Energy intake can be assessed using diet logs and dietary analysis programmes. Energy expenditure can be estimated by measuring or estimating RMR and exercise energy expenditure. RMR can be estimated using one of the several algorithms, ${ }^{109-111}$ and multiplying by an activity factor ${ }^{112} 113$ will account for exercise energy expenditure, thereby providing an estimate of total energy expenditure needs.

Step 2: Using the appropriate target for EA, meal plans should be developed that incorporate a variety of factors. Specifically, diet quality, diet variety, food preferences and practical aspects of food availability should be considered. Goals would include achieving an adequate balance of macronutrients and appropriate intake of micronutrients, particularly calcium, vitamin D, iron, zinc and vitamin $\mathrm{K}$. Whenever possible, the recommendation should be to increase intake of real foods versus dietary or meal supplements. Dietary recommendations should include incorporation of energy and nutrient-dense foods such as fortified milk drinks and essential fatty acids in the form of fish, healthy oils, nuts avocados and dried fruit. If there is a possibility of gastrointestinal discomfort with high caloric loads, small and frequent meals should be consumed throughout the day, with timing dependent on practice and competition. Particular attention should be paid to identifying times across the day where dietary energy intake may be particularly low. ${ }^{114}$ Adjustments in dietary strategies for increasing EA should also take into account changes across the season in accordance with competition schedules.

A successful treatment plan requires standardised periodic monitoring of body weight. Athletes should be weighed on the same scale, wearing minimal clothing, such as shorts and a t-shirt, to reduce the likelihood of falsifying their weight. ${ }^{115}$ The frequency of weight monitoring depends on the degree to which weight determines health and eligibility to participate in sport. A reasonable frequency is weekly when initiating a treatment programme. 


\section{Specific recommendations that target ED}

The goals of treatment for exercising women with ED is to normalise pathological eating behaviours, reduce dieting attempts and alter negative emotions and beliefs associated with food and body image. ${ }^{116}$ Cognitive behavioural therapy (CBT) has been demonstrated to be an effective treatment approach for exercising women with $\mathrm{ED}^{117-119}$ and may be more beneficial than nutritional counselling alone in some women with amenorrhoea particularly if DE behaviour is present. ${ }^{120}$ CBT may assist women with $\mathrm{DE}$ behaviours and body image disturbances to comply with an increased energy intake prescription and associated weight gain.

\section{Specific recommendations that target low BMD}

In exercising women with low BMD, the Panel recommendations include increasing EA and optimising weight gain and resumption of menses. ${ }^{121}$ Calcium and vitamin D status should be addressed.

The aetiology of bone loss among amenorrhoeic women includes energy deficiency-related factors and oestrogen deficiency. $^{7} 9122$ Thus, weight gain and subsequent resumption of menses are key to prevent further loss of bone mass. ${ }^{90}{ }^{95}$ It is estimated that amenorrhoeic women will lose approximately 2-3\% of bone mass per year if the condition remains untreated. ${ }^{90} 9596$ Data on recovery of bone mass in amenorrhoeic athletes secondary to increased energy intake are limited. However, significant improvements in bone health outcomes were observed in case studies of amenorrhoeic female athletes who gained weight. $^{105} 106$ In studies of anorexic women, investigators provide evidence of increases in BMD (1-10\%) associated with weight gain and resumption of menses, ${ }^{90} 95123124$ whereas, continual decreases in BMD were observed in those who did not recover menses. ${ }^{90}{ }^{95}$ Miller et $a l^{95}$ reported that resumption of menses occurred in 75 anorexic women who gained $4 \mathrm{~kg}$ of body mass, on an average, and the combined effects of weight gain and resumption of menses contributed to significant improvements in lumbar spine (3.1\%) and hip BMD (1.8\%). Misra et a $l^{90}$ demonstrated that menstrual recovery and weight gain attenuated further decreases in BMD in 34 anorexic girls aged 12-18 years over a 12-month period of time. In other prospective studies, similar findings are reported. ${ }^{124} 125$

In a retrospective study by Arends $e t a l,{ }^{89}$ percentage weight gain was identified as the strongest predictor of resumption of menses in female collegiate athletes, and may also be a predictor of gains in BMD. Findings from case reports ${ }^{105} 106$ and retrospective analyses ${ }^{89}$ published to date demonstrate that weight gain can lead to substantial increases in BMD in an energy replete environment. Prospective, randomised controlled trials (RCTs) are necessary in large samples of exercising women with amenorrhoea and low BMD to confirm the beneficial effects of increased body weight accomplished by increased energy intake on BMD.

Furthermore, substantial evidence exists in support of the positive effect of weight gain alone on BMD. Weight gain independent of resumption of menses has been shown to have a positive effect on BMD, and to restore the coupling of bone formation and resorption. ${ }^{90}{ }^{124-127}$ However, in spite of some recovery of bone mass, normalisation of BMD is unlikely to occur with weight gain alone. From a treatment standpoint, energy and oestrogen-dependent mechanisms of bone loss must be addressed in order to promote optimal increases in BMD. In summary, nutritional and hormonal recovery is recommended to improve mineralisation of trabecular bone and the growth of cortical bone. $^{90} 95128$
Weight-bearing exercise is a primary non-pharmacological strategy for increasing and maintaining BMD and geometry across the lifespan. ${ }^{129}$ Bone tissue is highly responsive to dynamic and high-magnitude loading, ${ }^{130}$ high-impact loading ${ }^{131-135}$ and resistance training. ${ }^{136}{ }^{137}$ Experiments in animals provide evidence of the positive effect of mechanical loading for optimising bone formation. ${ }^{138} 139$ In a recent meta-analysis $(\mathrm{n}=521 ; 7$ studies-randomised controlled exercise trials $\geq 24$ weeks) of the effects of exercise on BMD in premenopausal women, ${ }^{140}$ significant improvements in femoral neck and lumbar spine BMD were observed following weightbearing exercise training. This finding highlights the utility of exercise (aerobic, strength and/or high impact) for improving BMD at weight-bearing sites in premenopausal women. Specifically, programmes with a combination of high-impact loading and resistance training represent effective methods of optimising bone in the premenopausal years. ${ }^{141}$ Notably, in studies of the effect of high-impact loading or resistance training alone on BMD, investigators demonstrate mixed results. ${ }^{141} 142$ The majority of weight-bearing exercise interventions involved 2 or 3 days of training per week. ${ }^{141}$ For a review of the effects of exercise and bone, the reader is referred to the ACSM Position Stand on Bone Health and Exercise. ${ }^{143}$

To date, prospective studies are lacking wherein investigators explore the impact of resistance training and high-magnitude loading on the bone health of amenorrhoeic athletes. However, lean mass has been reported to be a strong predictor of hip BMD among anorexic adolescents ${ }^{144}$ and also adolescent athletes and non-athletes. ${ }^{145}$ In agreement with these results, a longitudinal study assessing skeletal recovery in anorexic women over the course of 6-69 months demonstrated that per cent change in FFM was a significant positive predictor of the change in hip and lumbar spine BMD and, furthermore, was a stronger predictor of BMD change than the change in fat mass or body weight. ${ }^{95}$ These results suggest that increases in lean mass may be an important component of weight recovery, and, as such, the lean mass gained through resistance training may be beneficial for BMD in amenorrhoeic athletes. Increases in lean mass may also be beneficial for increasing bone size, ${ }^{146}$ thus improving bone strength and decreasing the risk of fracture, and improving athletic performance.

The Panel expressed concerns that high-impact activity in females with low BMD ( \pm fractures) may in fact result in fracture. ${ }^{147}$ Further studies are necessary to determine the impact of combined weight-bearing programmes on BMD and fracture risk in athletes with low BMD. There is also the notion that oestrogen may be permissive for the osteogenic effects of mechanical loading, ${ }^{148}$ as data have demonstrated poor osteogenic benefits of mechanical loading in chronically amenorrhoeic athletes. ${ }^{128} 149150$

\section{What is the recommended time course of non-pharmacological treatment (including follow-up)?}

Treatment of the Triad conditions by increasing EA will result in recovery of physiological systems at different rates. Notably, the time to resumption of menses may vary among exercising women and is dependent on the severity of the energy deficiency and duration of menstrual dysfunction..$^{89} \quad 9094$ An increase in EA can positively alter metabolic hormone profiles within days to weeks, with concomitant changes in body weight occurring over weeks and months. Weight gain has been observed as a clinically positive outcome associated with resumption of menses and enhanced bone health in exercising women. ${ }^{879095105106}$ The recovery of menstrual function with strategies to increase EA can occur within several months ${ }^{94}$ but 
may take longer than 1 year. ${ }^{89}$ Improvements in BMD will occur more slowly, often over several years. Whether or not $\mathrm{BMD}$ can be restored to levels appropriate for age and training status remains unclear. ${ }^{151-153}$ A schematic of the time course of recovery of Triad factors is displayed in figure 3.

\section{Summary comments regarding non-pharmacological treatment}

Overall, successful treatment of athletes and exercising women is contingent on a multidisciplinary approach for recovery from the Triad, ${ }^{154}$ including a primary care and/or sports medicine physician, a sports dietitian and mental health practitioner. Depending on the individual situation, consultation from an endocrinologist, orthopaedic surgeon, psychiatrist, exercise physiologist, certified athletic trainer, family members and/or team coach (if applicable) may be helpful. This treatment approach is based on trusting and respectful interactions between healthcare providers and affected individuals. Consideration of the effects of treatment goals on health status, athletic performance and personal identity/lifestyle is necessary to ensure treatment compliance and post-treatment adherence by affected female athletes and exercising women.

\section{PHARMACOLOGICAL TREATMENT STRATEGIES FOR THE CLINICAL SEQUELAE OF THE TRIAD Overview}

Non-pharmacological measures should constitute initial management in female athletes with the Triad. For treatment of osteoporosis and/or in those athletes with multiple fracture history, the Panel emphasised that pharmacological management is to be considered if there is a lack of response to non-pharmacological therapy for at least 1 year and if new fractures occur during non-pharmacological management. Pharmacological management may also be necessary in the psychological treatment of $\mathrm{ED}$ and DE, especially if there are significant comorbid conditions.

\section{Low energy availability, disordered eating and eating disorders}

The Panel emphasised that low EA indicates that there is a problem, but does not differentiate between transient energy imbalance, DE and clinically significant ED. Individuals who have unintentional low EA or mild DE may respond well to nutritional education designed to eliminate low EA. Individuals with significant DE may benefit from counselling with a mental health practitioner, in addition to nutritional education. In contrast, individuals who have an ED require intensive interdisciplinary attention and treatment. The American Psychiatric Association Practice Guidelines for the Treatment of ED recommend a multidisciplinary team approach to treatment including a physician, mental health provider and sports dietitian. ${ }^{155}$ Results of small randomised trials involving treatment approaches that include mindfulness training, dialectical behaviour therapy and other therapeutic approaches are emerging. ${ }^{156} 157$ Antidepressant medications, particularly selective serotonin reuptake inhibitors, can be helpful in the treatment of bulimia nervosa. ${ }^{158}$ The APA Practice Guidelines describe limited evidence to use medications to restore weight, prevent relapse or treat chronic anorexia nervosa. Other psychotropic medications can be beneficial in treating comorbid conditions, such as anxiety, depression and obsessive compulsive behaviour. ${ }^{155}$

One of the challenges in addressing low EA is that it may be difficult to identify which individuals have an ED that requires more comprehensive treatment. This can be amplified by denial that there is a problem and minimisation of the difficulty in changing behaviours, which are common themes for individuals with ED. The team physician should work closely with the multidisciplinary team to determine the best treatment approach for an individual athlete. Readers are referred to the most recent Diagnostic and Statistical Manual of Mental Disorders, 5th ed (DSM-V) for full diagnostic criteria of ED. ${ }^{81}$

\section{Menstrual dysfunction}

Pharmacological strategies that target menstrual dysfunction are mostly experimental, as are strategies to optimise bone accrual in the adolescent athlete and to optimise BMD in adult athletes and exercising women, defined as at least 20 years old.

When considering pharmacological strategies to address amenorrhoea and hypoestrogenemia in athletes and exercising women, the Panel emphasised that it is essential to reiterate that combined oral or non-oral routes of contraceptive therapy do not restore spontaneous menses; indeed, contraceptive therapy simply creates an exogenous ovarian steroid environment that often provides a false sense of security when induced withdrawal bleeding occurs. ${ }^{159}$ Moreover, combined oral contraceptive (COC) therapy is not consistently associated with improved BMD in amenorrhoeic athletes ${ }^{160-162}$ and may in fact further compromise bone health given first-pass effects on hepatic production of insulin-like growth factor-1 (IGF-1), an important bone trophic hormone ${ }^{163-165}$ (details in 'Replacement of gonadal steroids' section). Therefore, the Panel emphasises that non-pharmacological treatment strategies should be prioritised, particularly focusing on achieving resumption of menses, ${ }^{95} 106$ given the importance of menses and normal oestrogen status to bone health. $^{8} 29128145166$

Consequences of hypogonadism (FHA) in athletes for which pharmacological treatment should be considered include:

- Symptoms of oestrogen deficiency, such as vaginal dryness and dyspareunia

- Infertility

- Impaired bone health (despite implementation of nonpharmacological therapy)

On the basis of the aetiopathogenesis of the Triad and the specific consequence of associated hypogonadism that requires treatment, several possible pharmacological strategies may be considered if non-pharmacological management is unsuccessful. This paper will address pharmacological options more specific to the consequence of impaired bone health.

\section{Replacement of gonadal steroids}

The major gonadal steroids include oestrogen, progesterone and testosterone, all of which are low in the amenorrhoeic athlete.

Oestrogen replacement: Overall, investigators have shown that oral oestrogen-progesterone combination pills are not an effective strategy to increase BMD in low-weight conditions such as anorexia nervosa (in adults and adolescents). ${ }^{167} 168$ Studies of COCs or hormone therapy in athletes with FHA are less definitive. ${ }^{169}$ Available studies in women with FHA include retrospective, ${ }^{170}{ }^{171}$ prospective ${ }^{172-174}$ and cohort studies ${ }^{175}{ }^{176}$; however, very few RCTs have been performed. ${ }^{160-162} 177$ In addition, most of these studies in women with FHA did not specifically target exercising women with FHA.

Pharmacological treatment that aims to restore regular menstrual cycles with COC does not normalise metabolic factors impairing bone health and will therefore likely not result in reversal of low BMD in the athlete with Triad disorders. ${ }^{2} 159172$ The lack of efficacy of oral oestrogen in improving BMD in 
conditions of low-weight and possibly normal-weight exerciseinduced amenorrhoea has been attributed to the suppressive effects of oral oestrogen on hepatic IGF-1 production. ${ }^{163} 164173$ IGF-1 is a bone trophic factor that is secreted by the liver in response to growth hormone and is also produced locally in an autocrine manner by target tissues such as bone. ${ }^{178}$ It is speculated that the first-pass effect of exogenous oestrogen through the liver suppresses IGF-1 production and upregulates the synthesis of binding proteins, such as IGFBP-1, which bind to IGF-1, further reducing its bioavailability. ${ }^{163}$ Given the low endogenous concentration of IGF-1 in amenorrhoeic athletes, ${ }^{145}$ a further reduction in IGF-1 levels secondary to the administration of oral oestrogen likely limits the beneficial antiresorptive effects of oestrogen. ${ }^{179}$ In addition, the type and dose of oestrogen have been implicated in the lack of efficacy of oral oestrogen in increasing BMD in energy-deficient states. ${ }^{168}$ As is stated in the 2007 ACSM Female Athlete Triad Position Stand, however, for women with FHA, increases in BMD are more closely associated with increases in weight than with COC administration, ${ }^{2}{ }^{161}$ so these treatments likely need to be implemented in combination with non-pharmacological treatment to optimise the effectiveness. ${ }^{161}$

Transdermal oestradiol administration when given in replacement doses does not suppress IGF- $1^{164} \quad{ }^{180-182}$ and therefore warrants further investigation as an alternative to COC therapy in the amenorrhoeic female athlete with the Triad. In a RCT in adolescent girls with anorexia nervosa, transdermal oestradiol administered at doses of $100 \mu \mathrm{g}$ twice weekly, along with cyclic progesterone $(2.5 \mathrm{mg}$ daily for 10 days of every month to prevent unopposed oestrogen stimulation of the uterus), increased their BMD without a reduction in IGF-1 levels. ${ }^{180}$ Bone accrual rates in girls with anorexia nervosa who received transdermal oestradiol approximated that in normal-weight controls after controlling for weight changes, and BMD Z-scores were maintained. ${ }^{180}$ However, bone accrual needs to exceed that in controls for 'catch-up' to occur and for BMD Z-scores to normalise to $>-1.0$. Likely because other hormonal alterations persist, catch-up does not always occur, as was shown in the same study. ${ }^{180}$ Although there are no published data regarding use of transdermal oestradiol in FHA, RCT studies are ongoing to address this possible treatment strategy, and further study is warranted.

Vaginal oestradiol administration also circumvents hepatic firstpass metabolism, and a vaginal oestrogen-progesterone combination contraceptive ring is now available. However, data regarding the impact of this form of oestrogen administration on BMD are conflicting with one study suggesting maintenance of BMD, and another suggesting that it may be deleterious to bone compared with no treatment in premenopausal women. ${ }^{183} 184$ Thus further research on vaginally applied oestrogen is necessary.

Data are limited regarding the impact of pharmacological therapies on muscle perfusion, although one study reported an improvement in endothelial dysfunction with use of $\mathrm{COC}$ therapy. $^{185}$

Testosterone replacement: The other gonadal hormone that is low in conditions of low weight and in amenorrhoeic athletes and exercising women is testosterone, which has antiresorptive effects (direct and oestrogen mediated) ${ }^{186} 187$ and also bone anabolic effects. ${ }^{187} 188$ There are no data available on testosterone administration in amenorrhoeic athletes and exercising women. However, a recent study in adult women with anorexia nervosa demonstrated no improvement in BMD with low-dose testosterone administration, despite increases in lean mass and initial increases in surrogate markers of bone formation. ${ }^{189}$
Normalising gonadotropin pulsatility and secretion

As stated earlier, the Panel contends that increasing EA through nutritional intervention is the best strategy for normalising gonadotropin pulsatility and secretion. From a pharmacological perspective, experimental strategies include administering hormones that are low in Triad conditions and that mechanistically can contribute to amenorrhoea and to low BMD, such as leptin and IGF-1, or administering antagonists of hormones that are high in Triad conditions and can contribute mechanistically to amenorrhoea and low BMD, such as ghrelin, peptide YY (PYY) and adiponectin.

Leptin: Few studies have examined the impact of administering metreleptin to women with FHA. ${ }^{190-192}$ Although metreleptin improved ovulatory status and increased BMC in women with FHA, the women sustained significant weight loss and reductions in fat mass, even when doses of the drug were carefully titrated. ${ }^{190-192}$ These data are concerning and suggest that leptin administration is not a good therapeutic strategy to normalise gonadotropin secretion and increase BMD in energy-deficient states, as in amenorrhoeic athletes and exercising women.

IGF-1 replacement: An important contributor to low BMD in amenorrhoeic athletes and exercising women is low IGF-1, particularly in those who are low weight. In adolescents and adults with anorexia nervosa, administering recombinant human IGF-1 (rhIGF-1) increases the levels of surrogate bone formation markers, ${ }^{193} 194$ and in one RCT in adult women with anorexia nervosa, giving rhIGF-1 (a bone anabolic hormone) with oral oestrogen (antiresorptive) led to a $2.8 \%$ significant increase in BMD when compared with the group that received neither. ${ }^{194}$ Data are lacking regarding the efficacy of rhIGF-1 administered alone or with oestrogen in improving bone health in exercise-induced amenorrhoea.

Other hormones: Although in vitro studies and studies in rodents have demonstrated that high ghrelin, PYY and adiponectin inhibit gonadotropin secretion, ${ }^{195-197}$ and high PYY and adiponectin are deleterious to bone, ${ }^{197-200}$ there are no data in animals or humans examining the impact of antagonists to these hormones on gonadotropin secretion and bone metabolism. In addition, a ghrelin antagonist runs the risk of eliminating the adaptive increase of an orexigenic stimulus, namely ghrelin, in this energy-deficient state.

\section{Bone mineral density}

Data are lacking regarding the efficacy of pharmacotherapy in treating low BMD with or without a fracture history in female athletes. While pharmacological therapy is recommended in postmenopausal women and men $\geq$ age 50 years ${ }^{201}$ with osteoporosis, the threshold for pharmacological treatment in the young female athlete with low BMD, stress fractures and/or impaired bone accrual is less clear.

It should be noted that the bones of amenorrhoeic and eumenorrhoeic athletes are subject to greater stress and strain secondary to specific athletic activities than that experienced by bones in non-athletes. ${ }^{202}$ Indeed, weight-bearing athletes should have higher BMD and other proxy indicators of bone strength secondary to chronic mechanical loading when compared with non-athletes. ${ }^{128} 130203$ The 2007 ACSM Position Stand on the Triad thus suggested that BMD Z-scores of $<-1.0$ in athletes involved in repetitive or high-impact stress may be low enough to increase fracture risk, especially in those with additional risk factors for the Triad. $^{2}$ In addition, athletes with Triad risk factors who sustain bone stress injuries may have a delay in return to sport. ${ }^{18}$ However, it is still not clear whether 
pharmacotherapy is beneficial in athletes with low BMD in the absence of a fracture history, and more importantly, whether or not treatment in this population prevents fractures and/or improves healing time and recovery in those who have sustained bone stress injuries.

Furthermore, some girls and women may have a genetically determined low peak bone mass, or may have had previous insults to the skeleton (such as poor nutrition and FHA) that have since resolved. In these cases, BMD may have stabilised, in contrast to a female athlete with ongoing low EA and amenorrhoea, who may have continued decreases in BMD, which could increase vulnerability to bone stress injury and fracture. Serial DXA measurements may be helpful in making this determination. There are currently no guidelines regarding the timing of initiation of pharmacological treatment in young female athletes with established osteoporosis or for DXA assessment and follow-up (boxes 2 and 3).

The Panel has concluded that the decision to treat or not with pharmacological therapies does not depend on BMD Z-scores alone, but also on additional risk factors such as fracture history, genetics, ${ }^{204}$ cumulative Triad risk factors, which have been associated with an increased risk for low BMD and bone stress injury, and rate of bone loss with non-pharmacological management. ${ }^{1746}$ The Panel suggests that the nature of athletic activity, response to non-pharmacological management as demonstrated by return of menses and/or as noted on serial DXA assessments, ${ }^{2}$ severity of the medical situation, fracture history and genetic predisposition should all play a role in the decision to treat with pharmacological therapy.

The Panel emphasised caution when considering FDA-approved postmenopausal treatment strategies for use in premenopausal women and children including Triad athletes and exercising women. Bisphosphonates have a very long halflife, and should be used with extreme caution in women of childbearing age for concerns of teratogenicity, ${ }^{205} 206$ although data to date are reassuring. The decision to initiate treatment with bisphosphonates in any premenopausal woman should be made on a case-by-case basis. Consideration should include individual fracture risk and potential medication-related adverse effects. There is concern regarding long-term use of bisphosphonates and the association with atypical femur fractures ${ }^{207} 208$ and osteonecrosis of the jaw. ${ }^{209}$ In addition, there are no published studies of bisphosphonate use in exercising and athletic women with Triad disorders. In one study in adult women with anorexia nervosa, bisphosphonate therapy (specifically risedronate) increased lumbar spine BMD compared with placebo ${ }^{189}$; however, a study in adolescent women with anorexia nervosa demonstrated no increase in spine BMD with alendronate given for a year. ${ }^{210}$ Bisphosphonates act by inhibiting bone resorption, and the differential effect of bisphosphonates in adults versus adolescents may relate to increased bone resorption in adults compared with a reduction in bone resorption in adolescents. ${ }^{211}$ There are a few special considerations for using bisphosphonates in the younger population, such as glucocorticoid-induced osteoporosis and osteogenesis imperfecta ${ }^{212-214}$ The Panel emphasised that any use of bisphosphonate therapy in young women with the Triad should only be executed by or in consultation with a board-certified endocrinologist or specialist in metabolic bone diseases. "It must be emphasized that the aforementioned pharmacological therapies are not currently approved by the FDA for increasing BMD or for fracture reduction in young or adult athletes.”189 215

To date, there are no published studies of denosumab or teriparatide use in girls and women with Triad disorders. A preliminary report in older women with anorexia nervosa demonstrated that treatment with teriparatide for 6 months increased bone formation (158\%) and lumbar spine BMD (anteroposterior spine 6\% and lateral spine 10.5\%) compared with placebo. ${ }^{216}$ There is also a case study that suggests that 4 weeks of teriparatide was associated with bone healing, reduced pain and resumption of normal activities in two premenopausal women with stress fractures. ${ }^{217}$

\section{Pharmacological treatment considerations}

Which athletes and exercising women should be targeted for pharmacological therapy?

The Panel emphasised that non-pharmacological therapy is the mainstay of treatment for all athletes with one or more components of the Triad.

The Panel concluded that there is no evidence at this time to unequivocally recommend pharmacological therapy in athletes with the Female Athlete Triad disorders due to lack of evidence-based research in this population. The Panel discussed that lack of response to non-pharmacological management (see definition below) may present a situation in which pharmacological therapy would be considered in an athlete with low BMD and a clinically significant fracture history. 'Pharmacological medications other than oestrogen and progesterone are not recommended in the absence of a fracture history'.

Pharmacological therapy may be considered in an athlete with:

- BMD Z-scores $\leq-2.0$ with a clinically significant fracture history (boxes 2 and 3; figure 4) AND lack of response to at least 1 year of non-pharmacological therapy (mainstay of treatment).

- BMD Z-scores between -1.0 and -2.0 with a clinically significant fracture history (boxes 2 and 3 ) and $\geq 2$ additional Triad risk factors ${ }^{17} 46$ (figure 4) AND lack of response to at least a year of non-pharmacological therapy.

Transdermal oestradiol replacement with cyclic progesterone may be considered in young athletes $\geq 16$ and $<21$ years of age with FHA to prevent further bone loss during this critical window of optimal bone accrual if they have

- BMD Z-scores $\leq-2.0$ without a clinically significant fracture history (boxes 2 and 3; figure 4) and at least one additional Triad risk factor ${ }^{17} 45$ (in addition to FHA; figure 4) AND lack of response to at least 1 year of non-pharmacological therapy.

Lack of response to therapy has been defined as

- A clinically significant reduction in BMD Z-scores after at least 1 year of non-pharmacological therapy, or

- Occurrence of new clinically significant fractures during nonpharmacological treatment over the course of 1 year.

Further research is warranted to assess the outcomes of pharmacological management and potential risks in this population. Although stress fractures are generally believed to be less concerning than non-stress fractures, they are a common and frequent cause of morbidity, time away from training and competition in athletes and loss of school and work days. In certain instances, these stress fractures can progress to devastating complete fractures at high-risk sites, such as the femoral neck, 218219 with consequences that can result in surgery and negatively affect exercise activity and quality of life. Of note, prolonged non-pharmacological management despite lack of response is of concern in younger athletes who are in the process of accruing peak bone mass, because the adolescent and young adult years 


\begin{tabular}{|c|c|c|c|}
\hline \multirow{2}{*}{ Risk Factors } & \multicolumn{3}{|c|}{ Magnitude of Risk } \\
\hline & Low Risk $=0$ points each & Moderate Risk $=1$ point each & High Risk $=2$ points each \\
\hline $\begin{array}{l}\text { Low EA with or without } \\
\text { DE/ED }\end{array}$ & $\square$ No dietary restriction & $\begin{array}{l}\square \text { Some dietary restrictionf; } \\
\text { current/past history of DE; }\end{array}$ & $\square_{\text {ED* }}$ Meets DSM-V criteria for \\
\hline Low BMI & $\begin{array}{l}\square \text { BMI } \geq 18.5 \text { or } \\
\geq 90 \% \mathrm{EW}^{* *} \text { or } \\
\text { weight stable }\end{array}$ & $\begin{array}{l}\square \text { BMI } 17.5<18.5 \text { or } \\
<90 \% \text { EW or } \\
5 \text { to }<10 \% \text { weight loss } / \text { month }\end{array}$ & $\begin{array}{c}\square \text { BMI } \leq 17.5 \text { or }<85 \% \text { EW or } \\
\geq 10 \% \text { weight loss } / \text { month }\end{array}$ \\
\hline Delayed Menarche & $\square$ Menarche $<15$ years & $\square$ Menarche 15 to $<16$ years & $\square$ Menarche $\geq 16$ years \\
\hline $\begin{array}{l}\text { Oligomenorrhea and/or } \\
\text { Amenorrhea }\end{array}$ & $\square>9$ menses in 12 months* & $\square$ 6-9 menses in 12 months* & $\square<6$ menses in 12 months* \\
\hline Low BMD & $\square$ Z-score $\geq-1.0$ & $\square$ Z-score $-1.0^{* * *}<-2.0$ & $\square$ Z-score $\leq-2.0$ \\
\hline Stress Reaction/Fracture & $\square$ None & $\square_{1}$ & $\begin{array}{c}\square \geq 2 ; \geq 1 \text { high risk or of } \\
\text { trabecular bone sites } \dagger\end{array}$ \\
\hline $\begin{array}{l}\text { Cumulative Risk } \\
\text { (total each column, then } \\
\text { add for total score) }\end{array}$ & ${ }_{\text {points }}$ & $C_{\text {points }}$ & $\chi_{\text {points }}={ }_{\text {T Total Score }}$ \\
\hline
\end{tabular}

Figure 4 Female Athlete Triad: Cumulative Risk Assessment. The cumulative risk assessment provides an objective method of determining an athlete's risk using risk stratification and evidence-based risk factors for the Female Athlete Triad. ${ }^{16} 1746$ This assessment is then used to determine an athlete's clearance for sport participation (figure 5). ¥Some dietary restriction as evidenced by self-report or low/inadequate energy intake on diet logs; * current or past history ${ }^{41} 57 ;{ }^{* *} \geq 90 \%$ EW $^{66} 91100107$; absolute BMI cut-offs should not be used for adolescents. ${ }^{* *}$ Weight-bearing sport ${ }^{2}$; † high-risk skeletal sites associated with low BMD and delay in return to play in athletes with one or more components of the Triad include stress reaction/fracture of trabecular sites (femoral neck, sacrum, pelvis). ${ }^{18} 83 \mathrm{BMD}$, bone mineral density; BMI, body mass index; $\mathrm{DE}$, disordered eating; $E A$, energy availability; EW, expected weight; ED, eating disorder.

are a critical window in time during which to optimise bone accrual, ${ }^{149}{ }^{220}$ and deficits incurred at this time may be irreversible. $^{152}$

As stated, there are no current treatments approved by the FDA for this specific population. ${ }^{215}$ Further research on pharmacological treatment alternatives is needed in this higher risk group of athletes with low BMD and a fracture history, as well as those with low BMD without a fracture history.

\section{What therapy can we offer?}

Increasing EA and optimising energy status

- The Panel unanimously agreed that all athletes and exercising women, particularly those who are considered candidates for pharmacological therapy, should be counselled regarding lifestyle and behavioural changes to increase EA and optimise energy status.

- Non-pharmacological management should continue, even if pharmacological therapy is prescribed.

Calcium and vitamin D

- Calcium-rich foods should be recommended with optimal calcium intake between 1000 and $1300 \mathrm{mg} /$ day. ${ }^{221}$

- Vitamin D status should be optimised. Daily intake of 600 IU of vitamin D is recommended by the Institute of Medicine for adolescents and adults up to age $70 .{ }^{221}$ Higher doses may be needed if they are deficient or insufficient in vitamin D. The Panel recommended that vitamin D levels be maintained between 32 and $50 \mathrm{ng} / \mathrm{mL}^{222}$

Oestrogen administration in female athletes with FHA or prolonged oligomenorrhoea who have failed non-pharmacological management

- In athletes and exercising women with FHA and prolonged amenorrhoea of hypothalamic origin who meet criteria for pharmacological therapy, a reasonable option is oestrogen administration with cyclic progesterone after ruling out other causes of amenorrhoea. It is also essential to consider contraceptive needs of the athlete. Before starting therapy, a thorough history and examination should be conducted to rule out contraindications for oestrogen therapy.

- COC therapy containing 20-35 $\mu$ g of ethinyl oestradiol may maintain BMD in those with very low BMD measures, although data are not definitive. ${ }^{168} 172$ Most of the studies in adolescents and adults with anorexia nervosa and in amenorrhoeic athletes suggest that COC therapies are not effective

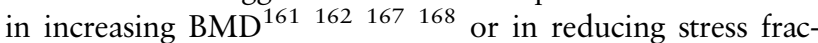
tures, ${ }^{161}$ although they are effective for contraceptive needs when used in recommended doses.

- Transdermal oestradiol $(100 \mu \mathrm{g}$ of $17 \beta$ oestradiol) with cyclic progesterone maintains BMD Z-scores in adolescents with anorexia nervosa, ${ }^{180}$ and is a consideration for low-weight, amenorrhoeic athletes who meet criteria for pharmacological intervention. Athletes who are symptomatic with this dose for oestrogen-related side effects such as nausea, bloating and breast tenderness may be started on a lower dose of the transdermal patch $(50 \mu \mathrm{g})$ and the dose increased to $100 \mu \mathrm{g}$ after 1 month.

- Cyclic progesterone is necessary in those on transdermal oestradiol to avoid deleterious effects of unopposed oestrogen on the uterine lining, and we recommend $200 \mathrm{mg}$ of micronised progesterone or 5-10 mg of medroxy progesterone acetate for 12 days of every month. 223224

- Of importance, the combination of transdermal oestradiol and cyclic oral progesterone in the described doses has unproven contraceptive efficacy, and other contraceptive methods are necessary if contraception is desired.

- If oestrogen replacement is considered in an athlete with a known or family history of thrombophilic disorders, we recommend consulting with a haematologist to assess whether tailoring the oestrogen dose, route and regimen to minimise risk is an option, with full written informed consent of the patient. $^{225}$ If oestrogen replacement is instituted, 
management should include ongoing follow-up with a haematologist.

- Testosterone, DHEA, leptin or rhIGF-1 replacement is not recommended at this time in athletes who meet criteria for pharmacological therapy, due to lack of studies in the female athlete population and potential adverse effects.

When should pharmacological options other than oestrogen be considered as options for treatment?

Pharmacological options other than oestrogen replacement/ COC

- In rare instances, pharmacological management other than oestrogen replacement/COC therapy can be considered when athletes meet the criteria for osteoporosis and have failed non-pharmacological therapy (with recurrent fractures), and meet one of the following criteria

- Contraindications to oestrogen;

- Lack of response to oestrogen replacement after $\geq 18$ 24 months in a compliant patient;

- Eumenorrhoeic athletes/exercisers (not hypoestrogenic) who meet criteria for therapy;

- Athletes with multiple debilitating fractures and significant morbidity.

- For the last two indications, patients should undergo a complete metabolic work-up, and genetic testing may be considered depending on the history of the patient and her family history.

- Other pharmacological options include bisphosphonates and teriparatide, which are effective strategies for treating postmenopausal osteoporosis ${ }^{226} 227$ and osteoporosis in special populations, ${ }^{212} 213$ but for whom data are limited, that is, in younger women, including female athletes. If such options are considered, the athlete/exerciser should be referred to an endocrinologist or an expert in metabolic bone diseases for further management, and treatment should be implemented only in conjunction with the endocrinologist or expert in metabolic bone disorders.

- Teriparatide is administered once daily as a subcutaneous injection and is bone anabolic. While this is a promising agent in adult athletes and studies are ongoing, data regarding its efficacy in a younger population are lacking at this time. Of note, this drug is contraindicated in pregnancy, and there is a black box warning for those at increased baseline risk for osteosarcoma, namely children with open epiphyses, individuals with unexplained elevations of alkaline phosphatase, those with Paget's disease and individuals with a prior history of external beam radiation therapy or implant radiotherapy of the skeleton (Product Information: FORTEO(R) subcutaneous solution, teriparatide subcutaneous solution. Eli Lilly and Company, Indianapolis, IN, 2004).

- Bisphosphonates are effective in increasing BMD in adult women with anorexia nervosa, ${ }^{189}$ but should be considered in athletes who meet criteria for pharmacological intervention with options other than oestrogen replacement, only when no other strategy is effective or when other strategies are contraindicated. Reproductive age women taking bisphosphonates should be prescribed birth control measures and counselled at length regarding the very long half-life of these medications and potential teratogenic effects on the fetus should pregnancy occur. If bisphosphonate therapy is prescribed, a time limit for these ongoing treatments, as in adults, should be considered due to potential risks of prolonged therapy. 205206

- There are no known studies using denosomab for osteoporosis treatment in premenopausal women or children, and thus this pharmacological alternative is not recommended and remains experimental in this group.

\section{CLEARANCE AND RETURN TO PLAY}

Despite widespread awareness and educational efforts on the Female Athlete Triad, ${ }^{2} 3228$ there have been no standardised guidelines for clearance and return to play. As a result, many female athletes with the Triad are being cleared at their preparticipation physical examination without being adequately assessed, managed or treated, and often return to play without structured follow-up.

\section{How can risk stratification be used to evaluate health and participation risk?}

Recent studies assessing health outcomes of single and combined risk factors for the Triad have demonstrated that there is an increased cumulative risk for the outcomes of low BMD, ${ }^{46}$ stress fracture and bone stress injury, ${ }^{16}{ }^{17}$ resulting in a doseresponse relationship that is related to the magnitude of risk of Triad disorders and subsequent impact on bone health and susceptibility to fracture. These findings are of significance with regard to management of the Triad, clearance and return to play, and emphasise the important role that risk stratification may have in optimising the athlete's health and minimising risk for injury and illness.

Prospective return-to-play data have demonstrated that female collegiate runners with menstrual dysfunction had more severe bone stress injuries on MRI compared with eumenorrhoeic runners. ${ }^{18}$ Low BMD and higher MRI grade bone stress injuries were independent predictors of delay in return to play. In addition, athletes with bone stress injuries in skeletal sites of predominantly trabecular bone structure (femoral neck, sacrum and pelvis) had a delay in return to play compared with those athletes with bone stress injuries at cortical bone sites. ${ }^{18}$ Marx et $a l^{83}$ found that female athletes with stress fractures in regions of mostly trabecular bone had lower BMD than those at cortical sites. These studies ${ }^{18}{ }^{83}$ highlight the importance of Triad risk factors on bone stress injury outcomes and the value of risk stratification. Future research is needed to assess the impact of Triad risk factors on return to play.

What is the role of the team physician in the return-to-play decision for Triad athletes?

According to the 2012 Consensus Statement on "The Team Physician and the Return to Play Decision," 229 the physician's duty is "to return an injured or ill athlete to practice or competition without putting the individual at undue risk for injury or illness." In addition, the team physician's role is to establish a return-to-play process, evaluate the athlete with medical conditions, treat and rehabilitate the athlete and return the athlete to play after it is determined to be safe to do so.

In summary, with increasing evidence that the athlete's risk for unfavourable outcomes of low BMD and/or bone stress injuries is greater with cumulative risk factors for the Triad, ${ }^{16}{ }^{17} 46$ evidence that Triad risk factors may contribute to more severe bone stress injuries and a delay in return to play, ${ }^{18}$ and due to the lack of standard of care guidelines for the Triad, the Panel recommends the following risk stratification protocol be implemented (figures 4 and 5). This risk stratification protocol has been translated into a worksheet for the physician (figure 4) that incorporates evidence-based risk factors for the Triad, ${ }^{16} 1746$ and takes into account the magnitude (or severity) of risk, assigning a point value for risk factors in each Triad spectrum based on risk severity (low, moderate and high risk). This cumulative risk 


\begin{tabular}{l|l|l|l|l}
\hline & $\begin{array}{l}\text { Cumulative } \\
\text { Risk Score* }\end{array}$ & Low Risk & Moderate Risk & High Risk \\
\hline Full Clearance & $0-1$ point & $\square$ & & $\square$ Provisional \\
Clearance & $\square$ Limited Clearance & \\
\hline $\begin{array}{l}\text { Provisional/Limited } \\
\text { Clearance }\end{array}$ & $2-5$ points & $\square$ points & $\begin{array}{l}\square \text { Restricted from } \\
\text { Training/ } \\
\text { Competition-Provisional } \\
\text { Restricted from Training } \\
\text { and Competition }\end{array}$ & $\geq 6$ Disqualified \\
\hline
\end{tabular}

Figure 5 Female Athlete Triad: Clearance and Return-to-Play (RTP) Guidelines by Medical Risk Stratification. * Cumulative Risk Score determined by summing the score of each risk factor (low, moderate, high risk) from the Cumulative Risk Assessment (figure 4). Clearance/RTP status for athletes moderate-to-high risk for the Triad: provisional clearance/RTP-clearance determined from risk stratification at time of evaluation (with possibility for status to change over time depending on athlete's clinical progress); limited clearance/RTP-clearance/RTP granted, but with modification in training as specified by physician (with possibility for status to change depending on clinical progress and new information gathered); restricted from training/competition (provisional) —athlete not cleared or able to RTP at present time, with clearance status re-evaluated by physician and multidisciplinary team with clinical progress; disqualified — not safe to participate at present time. Clearance status to be determined at future date depending on clinical progress, if appropriate. It is the recommendation of the Consensus Panel that athletes diagnosed with anorexia nervosa who have a body mass index (BMI) $<16 \mathrm{~kg} / \mathrm{m}^{2}$ or with moderate-to-severe bulimia nervosa (purging $>4$ times/week) should be categorically restricted from training and competition. Future participation is dependent on treatment of their eating disorder, including ascertainment of $\mathrm{BMI}>18.5 \mathrm{~kg} / \mathrm{m}^{2}$, cessation of bingeing and purging and close interval follow-up with the multidisciplinary team.

stratification protocol is then translated into clearance and return-to-play guidelines for the Triad based on the athlete's cumulative risk score (figure 5). Future research is needed to assess if implementation of a risk stratification model results in improved outcomes for female athletes with Triad disorders.

\section{Risk stratification and the multidisciplinary team}

Who are the members of the multidisciplinary team?

The Panel emphasised that the primary goal of the risk stratification protocol is to optimise health and reduce risk for injury and illness associated with the Female Athlete Triad. Best practice for outpatient management of the Triad can be accomplished with a multidisciplinary team consisting of the team physician, sports dietitian and often a mental health practitioner. ${ }^{102}$ Other team members may include the athlete's coach, athletic trainer, family members and other professionals, depending on the athlete's unique situation.

What are the recommendations for clearance and return to play based on risk stratification?

Athletes at low risk, by risk stratification for the Triad, can be fully cleared (assuming otherwise healthy). Referral to the multidisciplinary team for the low-risk athletes is not required, and can be individualised. Athletes at moderate risk for the Triad can be cleared provisionally or receive limited clearance. Provisional clearance would include clearance for full training/ competition, with the understanding that the athlete will be compliant with the recommendations outlined by the multidisciplinary team. With limited clearance, the athlete is cleared, but there are limitations specified with the athlete's training and competition, based on the athlete's health status. The athlete may be able to participate progressively in more training/competition as health status improves, as specified and outlined by the multidisciplinary team. It is recommended that athletes at moderate or high risk for the Triad be referred by the team physician to the appropriate multidisciplinary team member(s) and that a follow-up be scheduled to assess progress and review results of any tests ordered.

Those athletes determined to be at high risk are restricted from training and competition. In this category, the athlete's status can be provisional or the athlete may be disqualified. If the healthcare team determines that the athlete may be able to reach the stated health goals, the status is provisional, and a plan is outlined by the multidisciplinary team for a given period of time, and re-evaluated as the athlete's health status improves, if appropriate. If the severity of risk is determined to be too high for athletic participation at the time of the preparticipation examination, and prognosis determined to be poor, the athlete is disqualified and clearance/return to play re-evaluated with clinical progress, if appropriate. In such instances, the athlete may require more intensive outpatient treatment, inpatient hospitalisation or residential care prior to reassessment for clearance and return to play.

Similar to the FRAX algorithm developed by the WHO 230231 that uses clinical risk factors with or without BMD to assist with clinical decision-making in postmenopausal women and men to reduce fracture risk, it is hoped that this risk stratification developed for the Triad will assist healthcare providers working with female athletes to minimise risk associated with the Triad disorders. With ongoing research, updates to the risk stratification can be implemented in hopes of guiding treatment and decisionmaking for clearance and return to play.

\section{Treatment contracts}

How does the team physician utilise contracts?

Athletes in the moderate-risk and high-risk categories should receive a written contract that is reviewed and presented to them by the team physician after their initial evaluation. Although a verbal contract may be sufficient, the Panel recommends a written contract. The goal of the written contract is to specify the criteria necessary for ongoing or future clearance and return to play for the female athlete with the 
multidisciplinary team members, and to ensure a shared understanding of how the clinical status of the athlete will be followed with each member of the multidisciplinary team.

The team physician coordinates the treatment goals with each multidisciplinary team member, and includes the specific recommendations in the contract, in addition to the requested frequency of visits and expectations for each team member. The team physician then reviews the recommendations with the athlete, and answers any questions. In the case of the written contract, athlete and team physician sign the contract after it is discussed. (Please see online supplementary appendix for an example of a written contract for the Female Athlete Triad, which can be modified based on the athlete's clearance status.)

\section{Decision-based model for return to play}

What other factors play a role in clearance and the return-to-play decision?

In addition to risk stratification, the team physician must take into account the athlete's unique situation in making the final decision for clearance and return to play. ${ }^{232}$ The decision-based return-to-play model developed by Creighton et $a^{233}$ points out the complexities in return-to-play decision-making. There are medical factors and severity of risk considerations that need to be considered in the return-to-play decision. In addition, the return-to-play decision also involves consideration of sport risk modifiers (such as type of sport and competitive level) and willingness of the athlete to participate in her treatment. Athletes participating in leanness sports, for example, have been found to be at higher risk for Triad disorders. ${ }^{234}$ Although low BMI and/or low body weight are included as risk factors in the Triad risk stratification table (figure 4), it is important to recognise that low body fat is not independently associated with menstrual dysfunction, low BMD and stress fracture. ${ }^{19} 235$ It is not the recommendation of the expert Panel convened to systematically address body fat in female athletes, but to consider low body fat as a consequence of inadequate dietary intake and/or excessive exercise, and address those issues in the continuing effort to optimise EA, restore normal reproductive function and promote bone health. A decision-based model for the Triad, modified with permission from Creighton et al, ${ }^{233}$ illustrates some of the complex issues that need to be considered prior to the decision for clearance and return to play of the female athlete (figure 6).

In the evaluation of health risk and participation risk, an important consideration is also the age of the athlete. The preadolescent and adolescent athlete has more vulnerability to physeal and other skeletal injuries, especially during periods of rapid growth. Adolescence is a period of rapid bone mineral acquisition. $^{45} 149220$ Inadequate EA and menstrual dysfunction may result in a delay of bone mineralisation that lags behind bone linear growth. ${ }^{236}$ The mechanical stresses from repetitive loading in this population may increase susceptibility to fracture $^{147}$ in an already vulnerable area of bone, which may have potentially catastrophic consequences. Case reports of devastating displaced femoral neck stress fractures in female adolescent athletes with Triad disorders are concerning and suggest that better screening and management of the Triad is imperative to minimise future fracture risk and potential for life-long disability. $^{219} 237238$ Furthermore, prospective studies are needed to identify thresholds of physical activity and sport beyond which may be detrimental to bone health.

Similar scrutiny should be directed towards athletes meeting DSM-V criteria for an ED. ${ }^{81}$ While the presence of an ED is considered a high-risk attribute in the Cumulative Risk Factor Assessment (figure 4), it should be noted that patients with EDs have a higher risk of premature mortality when compared with

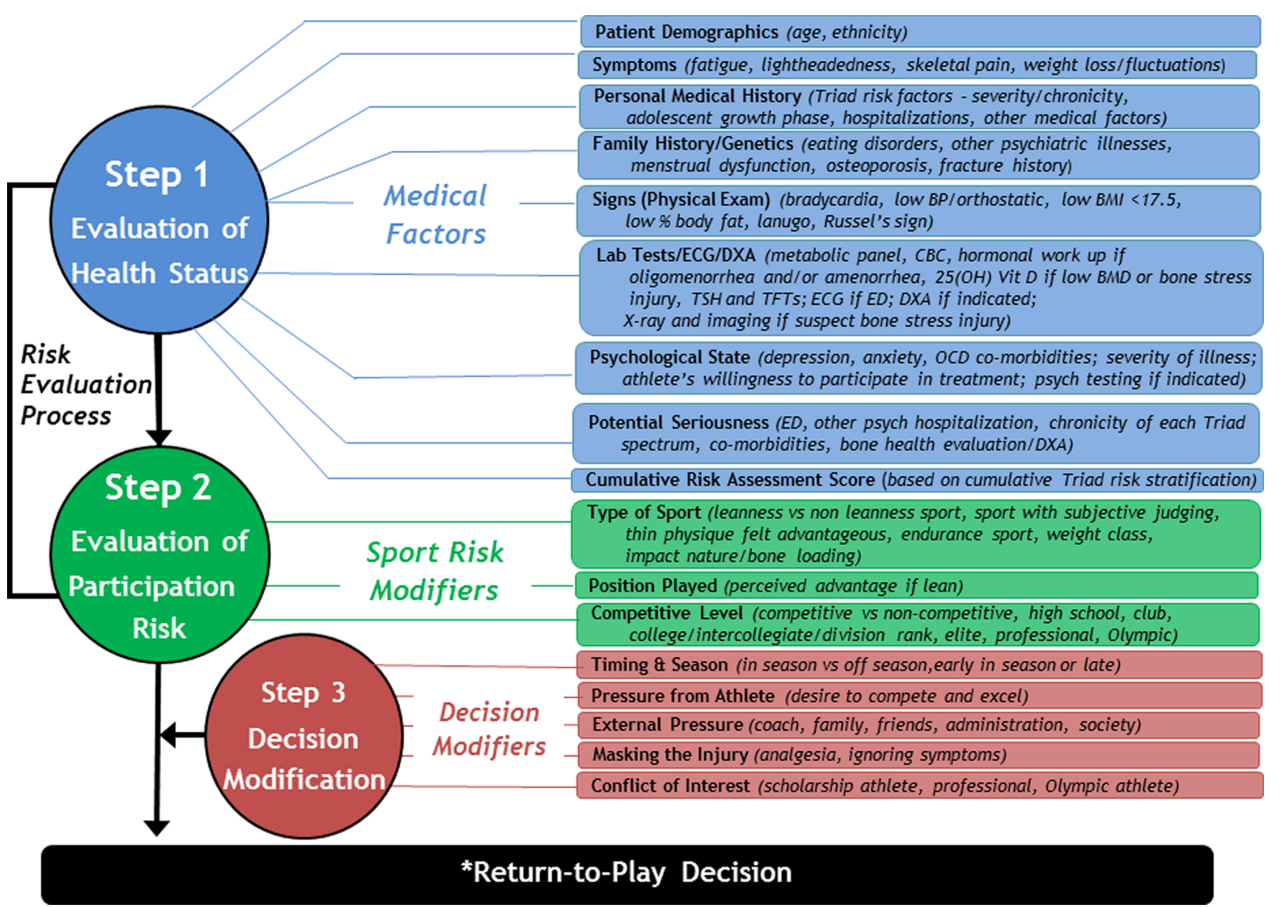

Figure 6 Decision-Based Return-to-Play (RTP) Model for the Female Athlete Triad. *RTP decision is determined by the primary care or team physician, and is based on a complex and comprehensive synthesis of health status, cumulative risk assessment, participation risk, sport and decision modifiers. 25(OH) Vit D, 25-hydroxyvitamin D; BMI, body mass index; BP, blood pressure; CBC, complete blood count; DXA, dual-energy X-ray absorptiometry; ED, eating disorder; OCD, obsessive compulsive disorder; TFTs, thyroid function tests; TSH, thyroid stimulating hormone; modified with permission from Creighton et al. 233 
individuals with other psychiatric diagnoses, and that is especially true for those with anorexia nervosa. ${ }^{239}$ Risk factors associated with a higher premature mortality rate among individuals with anorexia nervosa include: (1) longer duration of illness (>10 years); (2) lower BMI $\left(<16 \mathrm{~kg} / \mathrm{m}^{2}\right)$; (3) concurrent alcohol abuse and (4) poor social adjustment. ${ }^{239-241}$ It is the recommendation of the Consensus Panel that athletes diagnosed with anorexia nervosa who have a BMI $<16 \mathrm{~kg} / \mathrm{m}^{2}$ or with moderate-to-severe bulimia nervosa (purging $>4$ times/week) ${ }^{81}$ should be categorically restricted from training and competition. Future participation is dependent on treatment of their ED, including ascertainment of BMI $>18.5 \mathrm{~kg} / \mathrm{m}^{2}$, cessation of bingeing and purging and close interval follow-up with the multidisciplinary team. ${ }^{241}$

In some cases, participation in sport becomes fully integrated with an ED and isolation and treatment of the ED, such that resuming participation in the sport is not a realistic goal for the short or moderate term. It is important that EDs be recognised as a serious mental illness and that their impact and potentially long and pernicious course not be underestimated.

Finally, it is of paramount importance that the team physician has the ultimate say in the decision-making process for clearance and return to play. ${ }^{229} 232242$ Although the team physician has this authority to make the final decision, the decision is often the product of consultation with the multidisciplinary team, and other concerned parties. The physician must always have the athlete's health and safety as the first priority in the decisionmaking process, which should supersede all other pressures or circumstances that may arise.

\section{CONCLUSION}

Young girls and women with the Female Athlete Triad have significant health risks. Historically, many of these athletes have been cleared for sport participation without appropriate evaluation, management and treatment. Similarly, after medical illness or injury, athletes with the Triad often return to play prematurely, and without adequate treatment and follow-up. It is the team physician's responsibility to ensure that each and every athlete who is cleared for participation in sport or returning to play after an injury or illness return only when it is determined safe to do so. The 2014 Female Athlete Triad Coalition Consensus Statement on Treatment and Return to Play of the Female Athlete Triad Expert Panel has proposed an evidencebased risk stratification point system that takes into account the magnitude of risk to assist the physician in decision-making regarding sport participation, clearance and return to play. Guidelines are offered for clearance categories, management by a multidisciplinary team and implementation of treatment contracts. Future research is needed to study whether risk stratification, clearance and return-to-play guidelines are an effective means of optimising health and reducing risk for injury and illness for the Triad.

\section{Author affiliations}

'Department of Kinesiology, Penn State University, University Park, Pennsylvania, USA

${ }^{2}$ University of California Los Angeles, LOS Angeles, California, USA

${ }^{3}$ Intermountain Healthcare, Salt Lake City, Utah, USA

${ }^{4}$ Harvard Medical School, Boston, Massachusetts, USA

${ }^{5}$ University of Waterloo, Waterloo, Ontario, Canada

${ }^{6}$ University of Toronto, Toronto, Ontario, Canada

${ }^{7}$ Hospital for Special Surgery, New York, New York, USA

${ }^{8}$ Stanford University, Stanford, California, USA

Acknowledgements The authors and expert panel would like to acknowledge the contributions of Jim Whitehead, Executive Vice President and CEO, American
College of Sports Medicine; Mimi Johnson, MD; and Tyler Wadsworth, MD. Their encouragement, expertise and support contributed to the successful development of this document.

Expert Panel Members Michelle Barrack, PhD, RD, California State University Northridge, Northridge, California, USA; Louise Burke, PhD, Australian Institute of Sport, Australia; Barbara Drinkwater, PhD, FACSM, Washington, USA; Connie Lebrun, MD, University of Alberta, Edmonton, AB Canada; Anne B Loucks, PhD, Ohio University, Athens, Ohio, USA; Margo Mountjoy, MD, McMaster University, Guelph, Ontario Canada; Jeanne Nichols, PhD, San Diego State University, San Diego, California, USA; Jorunn Sungot Borgen, PhD, Norwegian School of Sport Sciences, Oslo, Norway.

Contributors All authors have contributed substantially to the manuscript and have been involved in designing and drafting the manuscript. MJDS, AN, EJ and MM planned, constructed and drafted the article and were also involved in revising the manuscript. NIW, MO, MG and GM were involved in drafting, reviewing and editing the manuscript. RJM and JCG were involved in writing and revising the manuscript and creating tables and figures. Members of the invited Expert Panel participated in Consensus Conference meetings held in June 2012 and June 2013 as well as provided the authors with guidance and feedback on the consensus process and manuscript.

\section{Competing interests None.}

Patient consent Obtained.

Provenance and peer review Not commissioned; externally peer reviewed.

\section{REFERENCES}

1 McCrory P, Meeuwisse W, Johnston K, et al. Consensus Statement on Concussion in Sport: the 3rd International Conference on Concussion in Sport held in Zurich, November 2008. Br J Sports Med 2009;43(Suppl 1):i76-90.

2 Nattiv A, Loucks AB, Manore MM, et al. American College of Sports Medicine position stand. The female athlete triad. Med Sci Sports Exerc 2007;39:1867-82.

3 Otis CL, Drinkwater B, Johnson M, et al. American College of Sports Medicine position stand. The female athlete triad. Med Sci Sports Exerc 1997;29:i-ix.

4 De Souza MJ, Lee DK, VanHeest JL, et al. Severity of energy-related menstrual disturbances increases in proportion to indices of energy conservation in exercising women. Fertil Steril 2007:88:971-5.

5 Williams $\mathrm{Nl}$, Helmreich $\mathrm{DL}$, Parfitt DB, et al. Evidence for a causal role of low energy availability in the induction of menstrual cycle disturbances during strenuous exercise training. J Clin Endocrinol Metab 2001;86:5184-93.

6 Loucks $A B$, Thuma JR. Luteinizing hormone pulsatility is disrupted at a threshold of energy availability in regularly menstruating women. J Clin Endocrinol Metab 2003;88:297-311.

7 De Souza MJ, West SL, Jamal SA, et al. The presence of both an energy deficiency and estrogen deficiency exacerbate alterations of bone metabolism in exercising women. Bone 2008:43:140-8.

8 De Souza MJ, Williams NI. Beyond hypoestrogenism in amenorrheic athletes: energy deficiency as a contributing factor for bone loss. Curr Sports Med Rep 2005:4:38-44.

9 Ihle $R$, Loucks $A B$. Dose-response relationships between energy availability and bone turnover in young exercising women. J Bone Miner Res 2004;19:1231-40.

10 Mallinson RJ, Williams NI, Hill BR, et al. Body composition and reproductive function exert unique influences on indices of bone health in exercising women. Bone 2013;56:91-100.

11 De Souza MJ, Miller BE, Loucks AB, et al. High frequency of luteal phase deficiency and anovulation in recreational women runners: blunted elevation in follicle-stimulating hormone observed during luteal-follicular transition. J Clin Endocrinol Metab 1998:83:4220-32.

12 De Souza MJ, Toombs RJ, Scheid JL, et al. High prevalence of subtle and severe menstrual disturbances in exercising women: confirmation using daily hormone measures. Hum Reprod 2010;25:491-503.

13 Tomten SE, Falch JA, Birkeland $\mathrm{KI}$, et al. Bone mineral density and menstrual irregularities. A comparative study on cortical and trabecular bone structures in runners with alleged normal eating behavior. Int J Sports Med 1998;19:92-7.

14 Sowers M, Randolph JF Jr, Crutchfield M, et al. Urinary ovarian and gonadotropin hormone levels in premenopausal women with low bone mass. J Bone Miner Res 1998;13:1191-202.

15 Field AE, Gordon CM, Pierce LM, et al. Prospective study of physical activity and risk of developing a stress fracture among preadolescent and adolescent girls. Arch Pediatr Adolesc Med 2011;165:723-8.

16 Tenforde AS, Sayres LC, McCurdy ML, et al. Identifying sex-specific risk factors for stress fractures in adolescent runners. Med Sci Sports Exerc 2013;45:1843-51.

17 Barrack MT, Gibbs JC, De Souza MJ, et al. Higher incidence of bone stress injury with increasing female athlete triad risk factors: a prospective multisite study of exercising girls and women. Am J Sports Med (in press). 
18 Nattiv A, Kennedy G, Barrack MT, et al. Correlation of MRI grading of bone stress injuries with clinical risk factors and return to play: a 5 -year prospective study in collegiate track and field athletes. Am J Sports Med 2013:41:1930-41.

19 Duckham RL, Peirce N, Meyer C, et al. Risk factors for stress fracture in female endurance athletes: a cross-sectional study. BMJ Open2012;2:e001920.

20 Kelsey JL, Bachrach LK, Procter-Gray E, et al. Risk factors for stress fracture among young female cross-country runners. Med Sci Sports Exerc 2007;39:1457-63.

21 Lauder TD, Dixit S, Pezzin LE, et al. The relation between stress fractures and bone mineral density: evidence from active-duty army women. Arch Phys Med Rehabil 2000;81:73-9.

22 Rauh MJ, Macera CA, Trone DW, et al. Epidemiology of stress fracture and lower-extremity overuse injury in female recruits. Med Sci Sports Exerc 2006;38:1571-7

23 Loucks $A B$, Heath EM. Induction of low-T3 syndrome in exercising women occurs at a threshold of energy availability. Am J Physiol 1994;266(3 Pt 2):R817-23.

24 Loucks $A B$, Verdun $M$, Heath $E M$. Low energy availability, not stress of exercise, alters LH pulsatility in exercising women. J Appl Physiol 1998;84:37-46.

25 Hilton LK, Loucks AB. Low energy availability, not exercise stress, suppresses the diurnal rhythm of leptin in healthy young women. Am J Physiol Endocrinol Metab 2000;278:E43-9.

26 Williams NI, Bullen BA, McArthur JW, et al. Effects of short-term strenuous endurance exercise upon corpus luteum function. Med Sci Sports Exerc 1999:31:949-58.

27 Williams NI, Caston-Balderrama AL, Helmreich DL, et al. Longitudinal changes in reproductive hormones and menstrual cyclicity in cynomolgus monkeys during strenuous exercise training: abrupt transition to exercise-induced amenorrhea. Endocrinology 2001;142:2381-9.

28 Loucks AB. Low energy availability in the marathon and other endurance sports. Sports Med 2007:37:348-52.

29 De Souza MJ, Williams NI. Physiological aspects and clinical sequelae of energy deficiency and hypoestrogenism in exercising women. Hum Reprod Update 2004;10:433-48

30 Bullen BA, Skrinar GS, Beitins IZ, et al. Induction of menstrual disorders by strenuous exercise in untrained women. N Engl J Med 1985:312:1349-53.

31 O'Donnell E, Harvey PJ, Goodman JM, et al. Long-term estrogen deficiency lowers regional blood flow, resting systolic blood pressure, and heart rate in exercising premenopausal women. Am J Physiol Endocrinol Metab 2007;292:E1401-9.

32 Rickenlund A, Eriksson MJ, Schenck-Gustafsson K, et al. Amenorrhea in female athletes is associated with endothelial dysfunction and unfavorable lipid profile. J Clin Endocrinol Metab 2005;90:1354-9.

33 Vanheest IL, Rodgers $C D$, Mahoney CE, et al. Ovarian suppression impairs sport performance in junior elite female swimmers. Med Sci Sports Exerc 2014:46:156-66

34 Becker AE, Grinspoon SK, Klibanski A, et al. Eating disorders. N Engl J Med 1999:340:1092-8.

35 Golden NH, Katzman DK, Kreipe RE, et al. Eating disorders in adolescents: position paper of the Society for Adolescent Medicine. J Adolesc Health 2003:33:496-503.

36 Rome ES, Ammerman S, Rosen DS, et al. Children and adolescents with eating disorders: the state of the art. Pediatrics 2003;111:e98-108.

37 Barrack MT, Ackerman KE, Gibbs JC. Update on the female athlete triad. Curr Rev Musculoskelet Med 2013:6:195-204.

38 Rumball JS, Lebrun CM. Preparticipation physical examination: selected issues for the female athlete. Clin J Sport Med 2004:14:153-60

39 Rumball JS, Lebrun CM. Use of the preparticipation physical examination form to screen for the female athlete triad in Canadian interuniversity sport universities. Clin J Sport Med 2005;15:320-5.

40 Ljungqvist $A$, Jenoure $P$, Engebretsen $L$, et al. The International Olympic Committee (IOC) Consensus Statement on periodic health evaluation of elite athletes March 2009. Br J Sports Med 2009:43:631-43.

41 American Academy of Family Physicians, American Academy of Pediatrics, American College of Sports Medicine, American Medical Society for Sports Medicine, American Orthopaedic Society for Sports Medicine, American Osteopathic Academy of Sports Medicine. In: Roberts W, Bernhardt D. eds Preparticipation Physical Evaluation, chapter 3. Timing, setting and structure. Pages 11-17. 4th edn. Elk Grove, IL: American Academy of Pediatrics, 2010.

42 Mencias T, Noon M, Hoch AZ. Female athlete triad screening in Nationa Collegiate Athletic Association Division I athletes: is the preparticipation evaluation form effective? Clin I Sport Med 2012;22:122-5.

43 Rauh MJ, Nichols JF, Barrack MT. Relationships among injury and disordered eating, menstrual dysfunction, and low bone mineral density in high school athletes: a prospective study. J Athl Train 2010:45:243-52.

44 Thein-Nissenbaum JM, Rauh MJ, Carr KE, et al. Menstrual irregularity and musculoskeletal injury in female high school athletes. J Athl Train 2012; 47:74-82.

45 Matkovic V, Jelic T, Wardlaw GM, et al. Timing of peak bone mass in Caucasian females and its implication for the prevention of osteoporosis. Inference from a cross-sectional model. J Clin Invest 1994:93:799-808.
46 Gibbs JC, Nattiv A, Barrack MT, et al. Low bone density risk is higher in exercising women with multiple Triad risk factors. Med Sci Sports Exerc 2014;46:167-76.

47 Francisco R, Narciso I, Alarcao M. Individual and relational risk factors for the development of eating disorders in adolescent aesthetic athletes and general adolescents. Eat Weight Disord 2013;18:403-11.

48 Gomes AR, Martins C, Silva L. Eating disordered behaviours in Portuguese athletes: the influence of personal, sport, and psychological variables. Eur Eat Disord Rev 2011;19:190-200.

49 Jacobi C, Fittig E, Bryson SW, et al. Who is really at risk? Identifying risk factors for subthreshold and full syndrome eating disorders in a high-risk sample. Psychol Med 2011;41:1939-49

50 Rosen LW, Hough DO. Pathogenic weight-control behaviors of female college gymnasts. Phys Sports Med 1988;16:140.

51 Liechty JM, Lee MJ. Longitudinal predictors of dieting and disordered eating among young adults in the U.S. Int I Eat Disord 2013;46:790-800.

52 Sundgot-Borgen J. Risk and trigger factors for the development of eating disorders in female elite athletes. Med Sci Sports Exerc 1994;26:414-19.

53 Thompson RA, Sherman RT. "Good athlete" traits and characteristics of anorexia nervosa: are they similar? Eating Disord 1999;7:181-90.

54 Sundgot-Borgen J, Torstveit MK. Aspects of disordered eating continuum in elite high-intensity sports. Scand J Med Sci Sports 2010;20(Suppl 2):112-21.

55 Leon GR. Eating disorders in female athletes. Sports Med 1991;12:219-27.

56 Thein-Nissenbaum JM, Rauh MJ, Carr KE, et al. Associations between disordered eating, menstrual dysfunction, and musculoskeletal injury among high school athletes. J Orthop Sports Phys Ther 2011:41:60-9.

57 Diaz A, Laufer MR, Breech LL. Menstruation in girls and adolescents: using the menstrual cycle as a vital sign. Pediatrics 2006;118:2245-50.

58 Scholes $\mathrm{D}$, LaCroix AZ, Ichikawa LE, et al. Change in bone mineral density among adolescent women using and discontinuing depot medroxyprogesterone acetate contraception. Arch Pediatr Adolesc Med 2005;159:139-44.

59 Loud KJ, Micheli LJ, Bristol S, et al. Family history predicts stress fracture in active female adolescents. Pediatrics 2007:120:E364-72.

60 Herring SA, Kibler WB, Putukian M, and expert panel. Selected issues for nutrition and the athlete: a team physician consensus statement. Med Sci Sports Exerc 2013:45:2378-86

61 Rodriguez NR, Di Marco NM, Langley S. American College of Sports Medicine position stand. Nutrition and athletic performance. Med Sci Sports Exerc 2009:41:709-31.

62 Deuster PA, Kyle SB, Moser PB, et al. Nutritional intakes and status of highly trained amenorrheic and eumenorrheic women runners. Fertil Steril 1986:46:636-43.

63 Kaiserauer S, Snyder AC, Sleeper M, et al. Nutritional, physiological, and menstrual status of distance runners. Med Sci Sports Exerc 1989:21:120-5.

64 Myerson M, Gutin B, Warren MP, et al. Resting metabolic rate and energy balance in amenorrheic and eumenorrheic runners. Med Sci Sports Exerc 1991:23: $15-22$.

65 Marcus R, Cann C, Madvig P, et al. Menstrual function and bone mass in elite women distance runners. Endocrine and metabolic features. Ann Intern Med 1985;102:158-63.

66 Le Grange D, Doyle PM, Swanson SA, et al. Calculation of expected body weight in adolescents with eating disorders. Pediatrics 2012;129:e438-46.

67 O'Donnell E, Harvey PJ, De Souza MJ. Relationships between vascular resistance and energy deficiency, nutritional status and oxidative stress in oestrogen deficient physically active women. Clin Endocrinol (Oxf) 2009;70:294-302.

68 Gibbs JC, Williams NI, Scheid JL, et al. The association of a high drive for thinness with energy deficiency and severe menstrual disturbances: confirmation in a large population of exercising women. Int I Sport Nutr Exerc Metab 2011;21:280-90

69 Scheid JL, Williams NI, West SL, et al. Elevated PYY is associated with energy deficiency and indices of subclinical disordered eating in exercising women with hypothalamic amenorrhea. Appetite 2009:52:184-92.

70 De Souza MJ, Hontscharuk R, Olmsted M, et al. Drive for thinness score is a proxy indicator of energy deficiency in exercising women. Appetite 2007:48:359-67.

71 Heaney S, O'Connor H, Gifford J, et al. Comparison of strategies for assessing nutritional adequacy in elite female athletes' dietary intake. Int I Sport Nutr Exerc Metab 2010;20:245-56.

72 Ainsworth BE, Haskell WL, Herrmann SD, et al. 2011 Compendium of physical activities: a second update of codes and MET values. Med Sci Sports Exerc 2011:43:1575-81.

73 Koehler $\mathrm{K}$, Braun H, De Marees $\mathrm{M}$, et al. Parallel assessment of nutrition and activity in athletes: validation against doubly labelled water, 24-h urea excretion, and indirect calorimetry. J Sports Sci 2010:28:1435-49.

74 Toombs RJ, Ducher G, Shepherd JA, et al. The impact of recent technological advances on the trueness and precision of DXA to assess body composition. Obesity (Silver Spring) 2012;20:30-9.

75 Meyer NL, Sundgot-Borgen J, Lohman TG, et al. Body composition for health and performance: a survey of body composition assessment practice carried out by the Ad Hoc Research Working Group on Body Composition, Health and Performance 
under the auspices of the IOC Medical Commission. Br J Sports Med 2013;47:1044-53.

76 Illingworth P. Amenorrhea, anovulation, and dysfunctional uterine bleeding. In: Jameson JL, De Groot LJ. eds Endocrinology adult and pediatric. 6th edn. St. Louis, MO: Saunders, an affiliate of Elsevier, Inc., 2010:2341-55.

77 The Practice Committee of the American Society for Reproductive Medicine. Current evaluation of amenorrhea. Fertil Steril 2004;82(Suppl 1):S33-9.

78 De Souza MJ, Toombs RJ. Amenorrhea associated with the female athlete triad: etiology, diagnosis and treatment. In: Santoro NF, Neal-Perry G. eds Amenorrhea: a case-based, clinical guide. Springer Science+Business Media, 2010:101-27.

79 Legro RS, Arslanian SA, Ehrmann DA, et al. Diagnosis and treatment of polycystic ovary syndrome: an Endocrine Society Clinical Practice Guideline. J Clin Endocrino Metab 2013;98:4565-92.

80 Lewiecki EM, Gordon CM, Baim S, et al. International Society for Clinica Densitometry 2007 Adult and Pediatric Official Positions. Bone 2008;43:1115-21.

81 American Psychiatric Association. Diagnostic and statistical manual of mental disorders. 5th edn. Arlington, VA: American Psychiatric Publishing, 2013.

82 Boden BP, Osbahr DC. High-risk stress fractures: evaluation and treatment. J Am Acad Orthop Surg 2000;8:344-53.

83 Marx RG, Saint-Phard D, Callahan LR, et al. Stress fracture sites related to underlying bone health in athletic females. Clin J Sport Med 2001;11:73-6.

84 Tannirandorn P, Epstein S. Drug-induced bone loss. Osteoporos Int 2000;11: 637-59.

85 Malabanan AO, Rosen HN, Vokes TJ, et al. Indications of DXA in women younge than 65 years and men younger than 70 years: the 2013 Official Positions. J Clin Densitom 2013;16:467-71

86 Gordon CM, Baim S, Bianchi ML, et al. Special report on the 2007 Pediatric Position Development Conference of the International Society for Clinical Densitometry. South Med J 2008;101:740-3.

87 Kopp-Woodroffe SA, Manore MM, Dueck CA, et al. Energy and nutrient status of amenorrheic athletes participating in a diet and exercise training intervention program. Int J Sport Nutr 1999:9:70-88.

88 Dueck CA, Matt KS, Manore MM, et al. Treatment of athletic amenorrhea with a diet and training intervention program. Int J Sport Nutr 1996:6:24-40.

89 Arends JC, Cheung MY, Barrack MT, et al. Restoration of menses with nonpharmacologic therapy in college athletes with menstrual disturbances: a 5-year retrospective study. Int J Sport Nutr Exerc Metab 2012;22:98-108.

90 Misra M, Prabhakaran R, Miller KK, et al. Weight gain and restoration of menses as predictors of bone mineral density change in adolescent girls with anorexia nervosa-1. J Clin Endocrinol Metab 2008;93:1231-7.

91 Golden NH, Jacobson MS, Schebendach J, et al. Resumption of menses in anorexia nervosa. Arch Pediatr Adolesc Med 1997;151:16-21.

92 Misra M, Prabhakaran R, Miller KK, et al. Role of cortisol in menstrual recovery in adolescent girls with anorexia nervosa. Pediatr Res 2006;59(4 Pt 1):598-603.

93 Misra M, Soyka LA, Miller KK, et al. Regional body composition in adolescents with anorexia nervosa and changes with weight recovery. Am J Clin Nutr 2003;77:1361-7.

94 Mallinson RJ, Williams NI, Olmsted MP, et al. A case report of recovery of menstrual function following a nutritional intervention in two exercising women with amenorrhea of varying duration. J Int Soc Sports Nutr 2013;10:34.

95 Miller KK, Lee EE, Lawson EA, et al. Determinants of skeletal loss and recovery in anorexia nervosa. J Clin Endocrinol Metab 2006:91:2931-7.

96 Audi L, Vargas DM, Gussinye M, et al. Clinical and biochemical determinants of bone metabolism and bone mass in adolescent female patients with anorexia nervosa. Pediatr Res 2002;51:497-504.

97 Hoch AZ, Jurva JW, Staton MA, et al. Athletic amenorrhea and endothelial dysfunction. WMJ 2007;106:301-6.

98 American Academy of Pediatrics. Medical concerns in the female athlete. Pediatrics 2000:106:610-13.

99 Temme KE, Hoch AZ. Recognition and rehabilitation of the female athlete triad/ tetrad: a multidisciplinary approach. Curr Sports Med Rep 2013;12:190-9.

100 Sherman RT, Thompson RA. Practical use of the International Olympic Committee Medical Commission Position Stand on the Female Athlete Triad: a case example. Int J Eat Disord 2006;39:193-201.

101 Beals KA. Disordered eating among athletes: a comprehensive guide for health professionals. Champaign, IL: Human Kinetics, 2004.

102 Joy EA, Wilson C, Varechok S. The multidisciplinary team approach to the outpatient treatment of disordered eating. Curr Sports Med Rep 2003;2: 331-6.

103 Sundgot-Borgen J. Weight and eating disorders in elite athletes. Scand J Med Sci Sports 2002;12:259-60.

104 Bratland-Sanda S, Sundgot-Borgen J. Eating disorders in athletes: overview of prevalence, risk factors and recommendations for prevention and treatment. Eur J Sport Sci 2013;13:499-508.

105 Zanker CL, Cooke CB, Truscott JG, et al. Annual changes of bone density over 12 years in an amenorrheic athlete. Med Sci Sports Exerc 2004:36:137-42.

106 Fredericson M, Kent K. Normalization of bone density in a previously amenorrheic runner with osteoporosis. Med Sci Sports Exerc 2005:37:1481-6.
107 Dominguez J, Goodman L, Sen Gupta S, et al. Treatment of anorexia nervosa is associated with increases in bone mineral density, and recovery is a biphasic process involving both nutrition and return of menses. Am J Clin Nutr 2007:86:92-9.

108 Joy E. Is the pill the answer for patients with the female athlete triad? Curr Sports Med Rep 2012;11:54-5.

109 Harris JA, Benedict FG. A biometric study of the basal metabolism in man. Washington, DC: Carnegie Institution of Washington, DC (Pub No 279), 1919:370-3.

110 Cunningham JJ. Body composition as a determinant of energy expenditure: a synthetic review and a proposed general prediction equation. Am J Clin Nutr 1991;54:963-9.

111 Frankenfield D, Roth-Yousey L, Compher C. Comparison of predictive equations for resting metabolic rate in healthy nonobese and obese adults: a systematic review. I Am Diet Assoc 2005;105:775-89.

112 Black AE, Coward WA, Cole TJ, et al. Human energy expenditure in affluent societies: an analysis of 574 doubly-labelled water measurements. Eur J Clin Nutr 1996;50:72-92.

113 FAO/WHO/UNU Expert Consultation. Energy and protein requirements. WHO Technical Report Series 724: 1-206. Geneva: World Health Organization, 1985.

114 Reed JL, De Souza MJ, Williams NI. Changes in energy availability across the season in division I female soccer players. J Sports Sci 2013:31:314-24.

115 Jaffa T, Davies S, Sardesai A. What patients with anorexia nervosa should wear when they are being weighed: report of two pilot surveys. Eur Eat Disord Rev 2011;19:368-70.

116 Zach KN, Smith Machin AL, Hoch AZ. Advances in management of the female athlete triad and eating disorders. Clin Sports Med 2011;30:551-73.

117 Brownley KA, Berkman ND, Sedway JA, et al. Binge eating disorder treatment: a systematic review of randomized controlled trials. Int J Eat Disord 2007; 40:337-48

118 Shapiro JR, Berkman ND, Brownley KA, et al. Bulimia nervosa treatment: a systematic review of randomized controlled trials. Int J Eat Disord 2007;40:321-36.

119 Wilfley DE, Bishop ME, Wilson GT, et al. Classification of eating disorders: toward DSM-V. Int J Eat Disord 2007;40(Suppl):S123-9.

120 Berga SL, Marcus MD, Loucks TL, et al. Recovery of ovarian activity in women with functional hypothalamic amenorrhea who were treated with cognitive behavior therapy. Fertil Steril 2003:80:976-81.

121 Winters-Stone KM, Snow CM. Musculoskeletal response to exercise is greatest in women with low initial values. Med Sci Sports Exerc 2003:35:1691-6.

122 Misra M, Klibanski A. Bone health in anorexia nervosa. Curr Opin Endocrinol Diabetes Obes 2011;18:376-82.

123 Viapiana O, Gatti D, Dalle Grave R, et al. Marked increases in bone mineral density and biochemical markers of bone turnover in patients with anorexia nervosa gaining weight. Bone 2007:40:1073-7.

124 Bolton JG, Patel S, Lacey JH, et al. A prospective study of changes in bone turnover and bone density associated with regaining weight in women with anorexia nervosa. Osteoporos Int 2005;16:1955-62.

125 Compston JE, McConachie C, Stott C, et al. Changes in bone mineral density body composition and biochemical markers of bone turnover during weight gain in adolescents with severe anorexia nervosa: a 1-year prospective study. Osteoporos Int 2006:17:77-84.

126 Heer M, Mika C, Grzella I, et al. Bone turnover during inpatient nutritional therapy and outpatient follow-up in patients with anorexia nervosa compared with that in healthy control subjects. Am J Clin Nutr 2004;80:774-81.

127 Hotta M, Shibasaki T, Sato K, et al. The importance of body weight history in the occurrence and recovery of osteoporosis in patients with anorexia nervosa: evaluation by dual X-ray absorptiometry and bone metabolic markers. Eur J Endocrinol 1998;139:276-83.

128 Ackerman KE, Nazem T, Chapko D, et al. Bone microarchitecture is impaired in adolescent amenorrheic athletes compared with eumenorrheic athletes and nonathletic controls. J Clin Endocrinol Metab 2011;96:3123-33.

129 Bailey CA, Brooke-Wavell K. Exercise for optimising peak bone mass in women. Proc Nutr Soc 2008;67:9-18.

130 Nikander $\mathrm{R}$, Sievanen $\mathrm{H}$, Heinonen $\mathrm{A}$, et al. Femoral neck structure in adult female athletes subjected to different loading modalities. J Bone Miner Res 2005;20:520-8.

131 Ramsdale SJ, Bassey EJ. Changes in bone mineral density associated with dietary-induced loss of body mass in young women. Clin Sci (Lond) 1994;87:343-8

132 Bassey EJ, Rothwell MC, Littlewood JJ, et al. Pre- and postmenopausal women have different bone mineral density responses to the same high-impact exercise. J Bone Miner Res 1998;13:1805-13.

133 Vainionpaa A, Korpelainen R, Leppaluoto J, et al. Effects of high-impact exercise on bone mineral density: a randomized controlled trial in premenopausal women. Osteoporos Int 2005:16:191-7.

134 Winters-Stone KM, Snow CM. Site-specific response of bone to exercise in premenopausal women. Bone 2006:39:1203-9.

135 Kato T, Terashima T, Yamashita T, et al. Effect of low-repetition jump training on bone mineral density in young women. J App/ Physiol 2006;100:839-43. 
136 Martyn-St James M, Carroll S. Progressive high-intensity resistance training and bone mineral density changes among premenopausal women: evidence of discordant site-specific skeletal effects. Sports Med 2006;36:683-704.

137 Wallace BA, Cumming RG. Systematic review of randomized trials of the effect of exercise on bone mass in pre- and postmenopausal women. Calcif Tissue Int 2000;67:10-18.

138 Lanyon LE. Functional strain in bone tissue as an objective, and controlling stimulus for adaptive bone remodelling. J Biomech 1987;20:1083-93.

139 Rubin CT, Lanyon LE. Regulation of bone mass by mechanical strain magnitude. Calcif Tissue Int 1985:37:411-17.

140 Kelley GA, Kelley KS, Kohrt WM. Exercise and bone mineral density in premenopausal women: a meta-analysis of randomized controlled trials. Int J Endocrinol 2013;2013:741639.

141 Martyn-St James M, Carroll S. Effects of different impact exercise modalities on bone mineral density in premenopausal women: a meta-analysis. J Bone Miner Metab 2010;28:251-67.

142 Kelley GA, Kelley KS. Efficacy of resistance exercise on lumbar spine and femoral neck bone mineral density in premenopausal women: a meta-analysis of individual patient data. J Womens Health (Larchmt) 2004;13:293-300.

143 Chodzko-Zajko WJ, Proctor DN, Fiatarone Singh MA, et al. American College of Sports Medicine position stand. Exercise and physical activity for older adults. Med Sci Sports Exerc 2009;41:1510-30.

144 Misra M, Miller KK, Cord J, et al. Relationships between serum adipokines, insulin levels, and bone density in girls with anorexia nervosa. I Clin Endocrinol Metab 2007:92:2046-52.

145 Christo K, Prabhakaran R, Lamparello B, et al. Bone metabolism in adolescent athletes with amenorrhea, athletes with eumenorrhea, and control subjects. Pediatrics 2008:121:1127-36.

146 Petit MA, Beck TJ, Lin HM, et al. Femoral bone structural geometry adapts to mechanical loading and is influenced by sex steroids: the Penn State Young Women's Health Study. Bone 2004;35:750-9.

147 Loud KJ, Gordon CM, Micheli LJ, et al. Correlates of stress fractures among preadolescent and adolescent girls. Pediatrics 2005;115:e399-406.

148 Saxon LK, Turner CH. Estrogen receptor beta: the antimechanostat? Bone 2005;36:185-92.

149 Ducher G, Bass SL, Saxon L, et al. Effects of repetitive loading on the growth-induced changes in bone mass and cortical bone geometry: a 12-month study in pre/peri- and postmenarcheal tennis players. I Bone Miner Res 2011:26:1321-9.

150 Ackerman KE, Putman M, Guereca G, et al. Cortical microstructure and estimated bone strength in young amenorrheic athletes, eumenorrheic athletes and non-athletes. Bone 2012;51:680-7.

151 Drinkwater BL, Nilson $\mathrm{K}$, Ott S, et al. Bone mineral density after resumption of menses in amenorrheic athletes. JAMA 1986;256:380-2.

152 Jonnavithula S, Warren MP, Fox RP, et al. Bone density is compromised in amenorrheic women despite return of menses: a 2-year study. Obstet Gynecol 1993;81(5 Pt 1):669-74.

153 Keen $A D$, Drinkwater BL. Irreversible bone loss in former amenorrheic athletes. Osteoporos Int 1997;7:311-15.

154 Nazem TG, Ackerman KE. The female athlete triad. Sports Health 2012; 4:302-11.

155 American Psychiatric Association (APA). Practice guideline for the treatment of patients with eating disorders. 3rd edn. 2006. http://psychiatryonline.org/pdfaccess. ashx?ResourcelD $=243187 \&$ PDFSource $=6$

156 Wanden-Berghe RG, Sanz-Valero J, Wanden-Berghe C. The application of mindfulness to eating disorders treatment: a systematic review. Eat Disord 2011:19:34-48

157 Yager J, Devlin MJ, Halmi KA, et al. Guideline watch (August 2012): practice guideline for the treatment of patients with eating disorders. 3rd edn. American Psychiatric Association, 2012. http://psychiatryonline.org/pdfaccess.ashx? ResourcelD $=5391825 \&$ PDFSource $=6$

158 Aigner M, Treasure J, Kaye W, et al. World Federation of Societies of Biological Psychiatry (WFSBP) guidelines for the pharmacological treatment of eating disorders. World I Biol Psychiatry 2011;12:400-43.

159 Bergstrom I, Crisby M, Engstrom AM, et al. Women with anorexia nervosa should not be treated with estrogen or birth control pills in a bone-sparing effect. Acta Obstet Gynecol Scand 2013:92:877-80.

160 Warren MP, Brooks-Gunn J, Fox RP, et al. Persistent osteopenia in ballet dancers with amenorrhea and delayed menarche despite hormone therapy: a longitudinal study. Fertil Steril 2003:80:398-404.

161 Cobb KL, Bachrach LK, Sowers M, et al. The effect of oral contraceptives on bone mass and stress fractures in female runners. Med Sci Sports Exerc 2007;39:1464-73

162 Gibson JH, Mitchell A, Reeve J, et al. Treatment of reduced bone mineral density in athletic amenorrhea: a pilot study. Osteoporos Int 1999;10:284-9.

163 Leung $\mathrm{KC}$, Johannsson G, Leong GM, et al. Estrogen regulation of growth hormone action. Endocr Rev 2004;25:693-721.
164 Weissberger AJ, Ho KK, Lazarus L. Contrasting effects of oral and transdermal routes of estrogen replacement therapy on 24-hour growth hormone (GH) secretion, insulin-like growth factor I, and GH-binding protein in postmenopausal women. J Clin Endocrinol Metab 1991;72:374-81.

165 Hansen M, Miller BF, Holm L, et al. Effect of administration of oral contraceptives in vivo on collagen synthesis in tendon and muscle connective tissue in young women. J Appl Physiol 2009;106:1435-43.

166 Cobb KL, Bachrach LK, Greendale G, et al. Disordered eating, menstrual irregularity, and bone mineral density in female runners. Med Sci Sports Exerc 2003:35:711-19.

167 Strokosch GR, Friedman AJ, Wu SC, et al. Effects of an oral contraceptive (norgestimate/ethinyl estradiol) on bone mineral density in adolescent females with anorexia nervosa: a double-blind, placebo-controlled study. J Adolesc Health 2006:39:819-27.

168 Klibanski A, Biller BM, Schoenfeld DA, et al. The effects of estrogen administration on trabecular bone loss in young women with anorexia nervosa. J Clin Endocrinol Metab 1995;80:898-904

169 Vescovi JD, Jamal SA, De Souza MJ. Strategies to reverse bone loss in women with functional hypothalamic amenorrhea: a systematic review of the literature. Osteoporos Int 2008;19:465-78

170 Hartard M, Kleinmond C, Kirchbichler A, et al. Age at first oral contraceptive use as a major determinant of vertebral bone mass in female endurance athletes. Bone 2004:35:836-41.

171 Cumming DC. Exercise-associated amenorrhea, low bone density, and estrogen replacement therapy. Arch Intern Med 1996:156:2193-5.

172 Rickenlund A, Carlstrom K, Ekblom B, et al. Effects of oral contraceptives on body composition and physical performance in female athletes. I Clin Endocrinol Metab 2004;89:4364-70.

173 Rickenlund A, Thoren M, Nybacka A, et al. Effects of oral contraceptives on diurnal profiles of insulin, insulin-like growth factor binding protein-1, growth hormone and cortisol in endurance athletes with menstrual disturbance. Hum Reprod 2010;25:85-93.

174 Warren MP, Miller KK, Olson WH, et al. Effects of an oral contraceptive (norgestimate/ethinyl estradiol) on bone mineral density in women with hypothalamic amenorrhea and osteopenia: an open-label extension of a double-blind, placebo-controlled study. Contraception 2005;72:206-11.

175 De Cree C, Lewin R, Ostyn M. Suitability of cyproterone acetate in the treatment of osteoporosis associated with athletic amenorrhea. Int J Sports Med 1988;9:187-92.

176 Gremion G, Rizzoli R, Slosman D, et al. Oligo-amenorrheic long-distance runners may lose more bone in spine than in femur. Med Sci Sports Exerc 2001;33:15-21.

177 Hergenroeder AC, Smith EO, Shypailo R, et al. Bone mineral changes in young women with hypothalamic amenorrhea treated with oral contraceptives, medroxyprogesterone, or placebo over 12 months. Am J Obstet Gynecol 1997;176:1017-25.

178 Ohlsson C, Bengtsson BA, Isaksson OG, et al. Growth hormone and bone. Endocr Rev 1998;19:55-79.

179 Lebow J, Sim L. The influence of estrogen therapies on bone mineral density in premenopausal women with anorexia nervosa and amenorrhea. Vitam Horm 2013:92:243-57.

180 Misra M, Katzman D, Miller KK, et al. Physiologic estrogen replacement increases bone density in adolescent girls with anorexia nervosa. J Bone Miner Res 2011;26:2430-8.

181 Kam K, Park Y, Cheon M, et al. Effects of immobilization stress on estrogen-induced surges of luteinizing hormone and prolactin in ovariectomized rats. Endocrine 2000:12:279-87.

182 Cardim HJ, Lopes CM, Giannella-Neto D, et al. The insulin-like growth factor-I system and hormone replacement therapy. Fertil Steril 2001;75:282-7.

183 Massaro M, Di Carlo C, Gargano V, et al. Effects of the contraceptive patch and the vaginal ring on bone metabolism and bone mineral density: a prospective, controlled, randomized study. Contraception 2010;81:209-14.

184 Massai R, Makarainen L, Kuukankorpi A, et al. The combined contraceptive vaginal ring and bone mineral density in healthy pre-menopausal women. Hum Reprod 2005;20:2764-8

185 Rickenlund A, Eriksson MJ, Schenck-Gustafsson K, et al. Oral contraceptives improve endothelial function in amenorrheic athletes. J Clin Endocrinol Metab 2005:90:3162-7.

186 Wiren KM, Zhang XW, Olson DA, et al. Androgen prevents hypogonadal bone loss via inhibition of resorption mediated by mature osteoblasts/osteocytes. Bone 2012;51:835-46.

187 Riggs BL, Khosla S, Melton LJ 3rd. Sex steroids and the construction and conservation of the adult skeleton. Endocr Rev 2002:23:279-302.

188 Abu EO, Horner A, Kusec $V$, et al. The localization of androgen receptors in human bone. J Clin Endocrinol Metab 1997:82:3493-7.

189 Miller KK, Meenaghan E, Lawson EA, et al. Effects of risedronate and low-dose transdermal testosterone on bone mineral density in women with anorexia nervosa: a randomized, placebo-controlled study. J Clin Endocrinol Metab 2011;96:2081-8.

190 Welt CK, Chan JL, Bullen J, et al. Recombinant human leptin in women with hypothalamic amenorrhea. N Engl J Med 2004;351:987-97. 
191 Sienkiewicz E, Magkos F, Aronis KN, et al. Long-term metreleptin treatment increases bone mineral density and content at the lumbar spine of lean hypoleptinemic women. Metabolism 2011;60:1211-21.

192 Chou SH, Chamberland JP, Liu X, et al. Leptin is an effective treatment for hypothalamic amenorrhea. Proc Natl Acad Sci USA 2011;108:6585-90.

193 Misra M, McGrane J, Miller KK, et al. Effects of rhlGF-1 administration on surrogate markers of bone turnover in adolescents with anorexia nervosa. Bone 2009;45:493-8.

194 Grinspoon S, Thomas L, Miller K, et al. Effects of recombinant human IGF-I and oral contraceptive administration on bone density in anorexia nervosa. J Clin Endocrinol Metab 2002;87:2883-91.

195 Kluge M, Schussler P, Uhr M, et al. Ghrelin suppresses secretion of luteinizing hormone in humans. J Clin Endocrinol Metab 2007;92:3202-5.

196 Lu M, Tang Q, Olefsky JM, et al. Adiponectin activates adenosine monophosphate-activated protein kinase and decreases luteinizing hormone secretion in LbetaT2 gonadotropes. Mol Endocrinol 2008;22:760-71.

197 Wen JP, Lv WS, Yang J, et al. Globular adiponectin inhibits GnRH secretion from GT1-7 hypothalamic GnRH neurons by induction of hyperpolarization of membrane potential. Biochem Biophys Res Commun 2008;371: 756-61.

198 Wong IP, Driessler F, Khor EC, et al. Peptide YY regulates bone remodeling in mice: a link between gut and skeletal biology. PLOS ONE 2012;7:e40038.

199 Luo XH, Guo LJ, Xie H, et al. Adiponectin stimulates RANKL and inhibits OPG expression in human osteoblasts through the MAPK signaling pathway. J Bone Miner Res 2006:21:1648-56.

200 Vulliemoz NR, Xiao E, Xia-Zhang L, et al. Decrease in luteinizing hormone pulse frequency during a five-hour peripheral ghrelin infusion in the ovariectomized rhesus monkey. J Clin Endocrinol Metab 2004;89:5718-23.

201 Watts NB, Lewiecki EM, Miller PD, et al. National Osteoporosis Foundation 2008 Clinician's Guide to Prevention and Treatment of Osteoporosis and the World Health Organization Fracture Risk Assessment Tool (FRAX): what they mean to the bone densitometrist and bone technologist. J Clin Densitom 2008;11:473-7.

202 Forwood MR, Burr DB. Physical activity and bone mass: exercises in futility? Bone Miner 1993;21:89-112.

203 Nikander R, Sievanen $\mathrm{H}$, Uusi-Rasi $\mathrm{K}$, et al. Loading modalities and bone structures at nonweight-bearing upper extremity and weight-bearing lower extremity: a pQCT study of adult female athletes. Bone 2006;39:886-94.

204 Estrada K, Styrkarsdottir U, Evangelou E, et al. Genome-wide meta-analysis identifies 56 bone mineral density loci and reveals 14 loci associated with risk of fracture. Nat Genet 2012;44:491-501.

205 Marini JC. Do bisphosphonates make children's bones better or brittle? N Engl J Med 2003;349:423-6.

206 Papapoulos SE, Cremers SC. Prolonged bisphosphonate release after treatment in children. N Engl J Med 2007;356:1075-6.

207 Desai PA, Vyas PA, Lane JM. Atypical Femoral fractures: a review of the literature. Curr Osteoporos Rep 2013;11:179-87.

208 Shane E, Burr D, Abrahamsen B, et al. Atypical subtrochanteric and diaphyseal femoral fractures: second report of a task force of the American Society for Bone and Mineral Research. J Bone Miner Res 2013 May 28. doi:10.1002/jbmr.1998

209 Khosla S, Burr D, Cauley J, et al. Bisphosphonate-associated osteonecrosis of the jaw: report of a task force of the American Society for Bone and Mineral Research. J Bone Miner Res 2007:22:1479-91.

210 Golden NH, Iglesias EA, Jacobson MS, et al. Alendronate for the treatment of osteopenia in anorexia nervosa: a randomized, double-blind, placebo-controlled trial. J Clin Endocrinol Metab 2005;90:3179-85.

211 Hoshino H, Takahashi M, Kushida K, et al. The relationships between the degree of beta-isomerization of type I collagen degradation products in the urine and aging, menopause and osteoporosis with fractures. Osteoporos Int 1999;9:405-9.

212 Bishop N, Adami S, Ahmed SF, et al. Risedronate in children with osteogenesis imperfecta: a randomised, double-blind, placebo-controlled trial. Lancet 2013.

213 Rizzoli R, Adachi JD, Cooper C, et al. Management of glucocorticoid-induced osteoporosis. Calcif Tissue Int 2012;91:225-43

214 Bachrach LK, Ward LM. Clinical review 1: bisphosphonate use in childhood osteoporosis. J Clin Endocrinol Metab 2009;94:400-9.

215 Bachrach LK, Sills IN. Clinical report-bone densitometry in children and adolescents. Pediatrics 2011;127:189-94.
216 Fazeli P, Wang I, Miller K, et al. Teriparatide increases bone formation and bone mineral density in adult women with anorexia nervosa. American Society of Bone and Mineral Research Annual Meeting 2013; Baltimore, MD [Abstract LB-SA33].

217 Raghavan $\mathrm{P}$, Christofides $\mathrm{E}$. Role of teriparatide in accelerating metatarsal stress fracture healing: a case series and review of literature. Clin Med Insights Endocrinol Diabetes 2012;5:39-45.

218 Goolsby MA, Nattiv AN, Casper J. Predictors for stress fracture and stress fracture rate in male and female collegiate track athletes: a prospective analysis. American Medical Society for Sports Medicine Annual Meeting. 2008

219 Okamoto S, Arai Y, Hara K, et al. A displaced stress fracture of the femoral neck in an adolescent female distance runner with female athlete triad: a case report. Sports Med Arthrosc Rehabil Ther Technol 2010;2:6.

220 Whiting SJ, Vatanparast $\mathrm{H}$, Baxter-Jones A, et al. Factors that affect bone mineral accrual in the adolescent growth spurt. J Nutr 2004;134:696S-700S.

221 Institute of Medicine. Dietary reference intakes for calcium and vitamin D. National Academy of Sciences; November 2010, Report Brief. http://wwwiomedu/ /media/ Files/Report\%20Files/2010/Dietary-Reference-Intakes-for-Calcium-and-Vitamin-D/ Vitamin\%20D\%20and\%20Calcium\%202010\%20Report\%20Briefpdf

222 Holick MF, Binkley NC, Bischoff-Ferrari HA, et al. Evaluation, treatment, and prevention of vitamin D deficiency: an Endocrine Society clinical practice guideline. J Clin Endocrinol Metab 2011:96:1911-30.

223 Food and Drug Administration. Prometrium Label. http://www.accessdata.fda.gov/ drugsatfda_docs/label/2009/019781s013lbl.pdf

224 Medroxyprogesterone Dosage. Drugs.com. http://www.drugs.com/dosage/ medroxyprogesterone.html

225 MacLennan AH. HRT in difficult circumstances: are there any absolute contraindications? Climacteric 2011;14:409-17.

226 Oswald AJ, Berg J, Milne G, et al. Teriparatide treatment of severe osteoporosis reduces the risk of vertebral fractures compared with standard care in routine clinical practice. Calcif Tissue Int 2013.

227 Eriksen EF, Halse J, Moen MH. New developments in the treatment of osteoporosis. Acta Obstet Gynecol Scand 2013:92:620-36.

228 Yeager KK, Agostini R, Nattiv A, et al. The female athlete triad: disordered eating, amenorrhea, osteoporosis. Med Sci Sports Exerc 1993:25:775-7.

229 Herring SA, Kibler WB, Putukian M. The team physician and the return-to-play decision: a consensus statement-2012 update. Med Sci Sports Exerc 2012;44:2446-8.

230 Kanis JA, Johnell 0, Oden A, et al. FRAX and the assessment of fracture probability in men and women from the UK. Osteoporos Int 2008;19:385-97.

231 McCloskey E, Kanis JA. FRAX updates 2012. Curr Opin Rheumatol 2012:24:554-60.

232 Herring SA, Kibler WB, Putukian M. Team Physician Consensus Statement: 2013 update. Med Sci Sports Exerc 2013;45:1618-22.

233 Creighton DW, Shrier I, Shultz R, et al. Return-to-play in sport: a decision-based model. Clin J Sport Med 2010;20:379-85.

234 Torstveit MK, Sundgot-Borgen J. Participation in leanness sports but not training volume is associated with menstrual dysfunction: a national survey of 1276 elite athletes and controls. Br J Sports Med 2005;39:141-7.

235 Kasa-Vubu JZ, Rosenthal A, Murdock EG, et al. Impact of fatness, fitness, and ethnicity on the relationship of nocturnal ghrelin to 24-hour luteinizing hormone concentrations in adolescent girls. J Clin Endocrinol Metab 2007;92: 3246-52.

236 Caine D, DiFiori J, Maffulli N. Physeal injuries in children's and youth sports: reasons for concern? Br J Sports Med 2006:40:749-60.

237 Goolsby MA, Barrack MT, Nattiv A. A displaced femoral neck stress fracture in an amenorrheic adolescent female runner. Sports Health 2012;4:352-6.

238 Haddad FS, Bann S, Hill RA, et al. Displaced stress fracture of the femoral neck in an active amenorrhoeic adolescent. Br J Sports Med 1997;31:70-2.

239 Smink FR, van Hoeken D, Hoek HW. Epidemiology of eating disorders: incidence, prevalence and mortality rates. Curr Psychiatry Rep 2012;14:406-14.

240 Zipfel S, Lowe B, Reas DL, et al. Long-term prognosis in anorexia nervosa: lessons from a 21-year follow-up study. Lancet 2000;355:721-2.

241 Franko DL, Keshaviah A, Eddy KT, et al. A longitudinal investigation of mortality in anorexia nervosa and bulimia nervosa. Am J Psychiatry 2013;170:917-25.

242 Matheson GO, Shultz R, Bido J, et al. Return-to-play decisions: are they the team physician's responsibility? Clin J Sport Med 2011;21:25-30. 